\title{
Les fortifications médiévales et modernes de Dinan (Côtes-d'Armor) : état des connaissances historiques et archéologiques
}

Dinan's medieval and modern fortifications (Côtes-d'Armor): state of historical and archaeological knowledge

Die mittelalterlichen und neuzeitlichen Befestigungsanlagen von Dinan (Côtes-

d'Armor): eine Übersicht zum historischen und archäologischen

Forschungsstand

Mickaël Dufeil

\section{(2) OpenEdition}

Édition électronique

URL : https://journals.openedition.org/rao/7932

DOI : $10.4000 /$ rao. 7932

ISSN : $1775-3732$

Éditeur

Presses universitaires de Rennes

Édition imprimée

Date de publication : 21 décembre 2021

Pagination : 245-274

ISBN : 978-2-7535-8668-0

ISSN : 0767-709X

Référence électronique

Mickaël Dufeil, « Les fortifications médiévales et modernes de Dinan (Côtes-d'Armor) : état des connaissances historiques et archéologiques », Revue archéologique de l'Ouest [En ligne], 37 | 2021, mis en ligne le 21 décembre 2021, consulté le 10 octobre 2022. URL : http://journals.openedition.org/rao/ 7932 ; DOI : https://doi.org/10.4000/rao.7932 


\title{
Les fortifications médiévales et modernes de Dinan (Côtes-d'Armor) : état des connaissances historiques et archéologiques
}

\author{
Dinan's medieval and modern fortifications (Côtes-d'Armor): \\ state of historical and archaeological knowledge
}

\author{
Mickaël Dufeil \\ Archéologue contractuel (dufeil.mickael@gmail.com)
}

\begin{abstract}
Résumé: En s'appuyant sur les sources textuelles de première main, les documents iconographiques et planimétriques anciens, ainsi que sur la reconnaissance des principales caractéristiques architecturales des ouvrages conservés, cette étude vise à faire le point sur l'état actuel des connaissances historiques et archéologiques relatives aux fortifications médiévales et modernes de Dinan. Les grandes étapes inhérentes à l'évolution des fortifications et au développement morphologique du tissu urbain sont abordées, comme la mise en place présumée d'une première clôture dans le courant du XII ${ }^{\mathrm{e}} s$., l'édification d'une grande enceinte de réunion aux XIII ${ }^{\mathrm{e}}$ et $\mathrm{XIV}^{\mathrm{e}}$ s., le renforcement et l'adaptation des fortifications à l'artillerie dans la seconde moitié du Xve s., l'installation d'une citadelle urbaine à la fin du XVI ${ }^{e}$ s., ainsi que la reprise des travaux de fortification à la fin du $\mathrm{XVII}^{\mathrm{e}} \mathrm{s}$. En dernier lieu, cet article présente les résultats d'une première étude de bâti conduite sur une partie du front nord, à la porte Saint-Malo et ses abords. Réalisée dans le cadre d'une opération d'archéologie programmée, cette analyse introduit quelques hypothèses inédites sur l'origine et l'évolution de cette partie des fortifications, et tend, par conséquent, à soulever de nouvelles interrogations.
\end{abstract}

\begin{abstract}
Based on primary written sources, cartographic documents, and the recognition of the main architectural characteristics of preserved constructions, this study's objective is to draw up a historical and archaeological overview of Dinan's medieval and modern fortifications. In this paper, we will look at the main phases of the fortifications and the development of the urban fabric. These include the first enclosure during the $12^{\text {th }}$ century, the building of a large global enclosure in the $13^{\text {th }}$ and $14^{\text {th }}$ centuries, the reinforcement and adaptation of the fortifications to artillery fire in the second half of the $15^{\text {th }}$ century, the installation of an urban citadel at the end of the $16^{\text {th }}$ century, as well as renovations dating to the end of the $17^{\mathrm{t}}$. Finally, this paper presents the results of a building study carried out on the northern front, around the Saint-Malo gate.
\end{abstract}

Mots clés: enceinte urbaine, fortifications urbaines, château, travaux de fortification, artillerie, archéologie du bâti, Dinan, Bretagne, Moyen Âge.

Keywords: defensive walls, urban fortifications, castle, fortification works, artillery, building archaeology, Dinan, Brittany, Middle Ages.

Les données historiques et archéologiques présentées dans cet article sont le résultat d'une étude de master réalisée à l'université Rennes $2^{1}$. Ces recherches ont pour but

1. Ce travail de recherche a été réalisé sous la codirection de P. -Y. Laffont (université Rennes 2) et E. Esnault (Inrap). II s’appuie entre autres sur les données collectées lors d'une opération de prospection effectuée sur une part des fortifications dinannaises, au nord de la ville close. Menée sous le contrôle scientifique du service régional d'archéologie de Bretagne (SRA), cette opération a donné lieu à la production d'un rapport de prospection thématique (Dufeil, 2020a). Ces données ont ensuite été intégrées à celles collectées pour l'ensemble de l'enceinte et présentées dans le cadre d'un mémoire universitaire (Dufeil, 2020b). de faire le point sur l'état des connaissances propres aux fortifications médiévales et modernes de Dinan, jusqu'ici peu étudiées sur le plan archéologique. A contrario, elles ont depuis longtemps suscité l'attention des historiens des textes et historiens de l'architecture. Les premières considérations remontent aux années 1830 et interviennent dans un contexte marqué par l'importance des destructions volontaires (Barral i Altet, 1988, p. 65-73; Geslin de Bourgogne, 1870). En 1886, les tours, murs et portes de la ville sont classés au titre des Monuments historiques. 
Dès lors, l'intérêt pour les vieilles murailles décline, et jusqu'au milieu du $\mathrm{XX}^{\mathrm{e}} \mathrm{s}$., la connaissance des fortifications dinannaises ne progresse guère. En 1950, R. Cornon livre une description des tours et portes de la ville, proposant pour chacune une datation approximative qui n'a que peu évolué depuis lors (Cornon, 1950). Sur le plan historique, en 1953, puis en 1968, M.-E. Monier consacre un large chapitre de sa monographie aux " remparts " de Dinan (Monier, 1977, p. 157-245). Le principal intérêt de ce travail réside dans la transcription de nombreux mandements relatifs aux travaux de fortification entrepris dans les années 1470-1480, sous le gouvernement du duc François II. Après quoi, dans les années 1980, l'effondrement de la tour Longue suscite un regain d'intérêt pour la question des fortifications de Dinan. Intérêt scientifique d'une part (Ronsseray, 1986; Barral i Altet, 1986) et intérêt patrimonial plus encore : en 1983, la Ville se lance dans un important projet de revalorisation et de restauration de l'ancienne muraille, qu'elle poursuit toujours, malgré les effondrements répétés. Plus décisives encore, les années 1990 sont marquées par l'essor considérable des connaissances relatives aux défenses dinannaises. Sur le terrain opérationnel tout d'abord, quelques sondages archéologiques sont réalisés pour la première fois au pied de la muraille et dans les anciennes douves ${ }^{2}$. À cette occasion notamment, la Ville fait exhumer les restes de l'ancienne porte de l'Hôtellerie, démolie en 1881 sur demande de la municipalité de l'époque. Durant ces mêmes années, elle lance un vaste programme de restauration, principalement focalisé sur le quart nord-est de l'enceinte. Sur le plan scientifique, C. Corvisier publie une synthèse mettant à l'honneur les ouvrages dinannais caractéristiques des XIII ${ }^{e}$ et XV ${ }^{e}$ s. (Corvisier, 1999). Toutefois, la décennie 1990 est surtout marquée par l'œuvre de S. Gesret : dès 1990, celui-ci réalise un premier travail de maîtrise consacré à l'étude architecturale et archéologique des portes de Dinan, complété en 1993 par un travail de DEA, portant cette fois sur les tours de Dinan (Gesret, 1990; 1993). En 1998, l'ensemble bénéficie d'une publication de synthèse (Gesret, 1998). Cet ouvrage offre un panorama complet des tours et portes de la ville, qu'elles soient en élévation ou disparues. L'ensemble pèche néanmoins par l'absence de traitement des courtines, la faiblesse des démonstrations graphiques et photographiques et le manque de comparaisons avec d'autres ouvrages connus. Ce premier travail de fond n'en reste pas moins un outil fondamental pour qui souhaite approfondir l'analyse de tout ou partie des ouvrages. Depuis lors cependant, et à l'exception de quelques recherches opérées ces dernières années dans

2. Trois opérations de sondages archéologiques ont été réalisées de 1990 à 1993 aux abords de la place Duclos et à hauteur de la rue de la Croix. Les rapports sont consultables en ligne sur la base numérique du SRA. l'enceinte du "château ${ }^{3}$ ", aucune étude n'a permis de renouveler l'état des connaissances propres à l'enceinte urbaine de Dinan.

Le but de cette étude consiste donc à faire le point sur l'état actuel des connaissances touchant à l'évolution des fortifications médiévales et modernes de Dinan, de façon à faciliter les recherches à venir. Cette synthèse s'appuie autant que possible sur les sources textuelles de première main, les documents iconographiques et planimétriques anciens, ainsi que sur la reconnaissance des principales caractéristiques architecturales des ouvrages conservés 4 . Au-delà d'un simple aspect synthétique, cette étude tend également à présenter les résultats d'une première analyse de bâti menée sur le front nord, aux abords de la porte Saint-Malo.

\section{LES FORTIFICATIONS DE DINAN AU TEMPS DES PREMIERS SEIGNEURS (XI $I^{\mathrm{e}}-\mathrm{XII}{ }^{\mathrm{e}} \mathrm{S}$.)}

\section{La naissance et le développement du bourg castral}

Le site de Dinan est localisé au nord-est du département des Côtes-d'Armor, sur la rive occidentale de la Rance et à près de $30 \mathrm{~km}$ au sud de son embouchure. Là, le rythme des occupations humaines suit la progression du niveau marin (Bachelier, 2014, p. 210-211) [fig. 1]. À partir de la seconde moitié du viII ${ }^{\mathrm{e}}$ s., la transgression marine favorise la progression des voies navigables jusqu'au plateau de Dinan. Selon la tradition hagiographique, un monastère est fondé à Léhon dès le milieu du Ix ${ }^{\mathrm{e}} \mathrm{s}$., à moins de $2 \mathrm{~km}$ au sud de Dinan (La Borderie, 1891). Ravagé au siècle suivant par les Normands, il est rebâti au début du XI ${ }^{\mathrm{e}}$ s., probablement à l'emplacement de l'abbaye romane.

La première mention des seigneurs de Dinan remonte à l'an 1040 (Dom Morice, t. I, col. 393). Issu d'un important lignage vicomtal, maître de la région doloise, Josselin de Dinan ancre le cœur de son pouvoir sur le rebord oriental d'un vaste plateau surmontant le cours de la Rance, à l'endroit où les flancs de l'estuaire se resserrent. Le choix de cette implantation est stratégique : la force de l'escarpement offre une assise confortable et un retranchement utile pour dominer le territoire environnant, tandis que l'essor des voies navigables jusqu'en ce point de la vallée favorise l'établissement d'un port fluvial. En parallèle, les flancs resserrés de la ria permettent la construction d'un pont et les

3. Des opérations de diagnostic et de fouille ont été menées au pied de la tour ducale et dans l'enceinte de la cour haute érigée à la fin du Xvi ${ }^{e}$ s. Les rapports sont consultables sur la bibliothèque numérique du SRA.

4. Nous n'avons pas pu bénéficier de tous les accès dont a profité S. Gesret. Une grande partie de notre travail reste donc tributaire du sien. Dans la mesure où les plans d'ouvrage proposés par l'auteur ne sont pas toujours exacts et/ou complets, le travail de relevé reste donc à faire. 


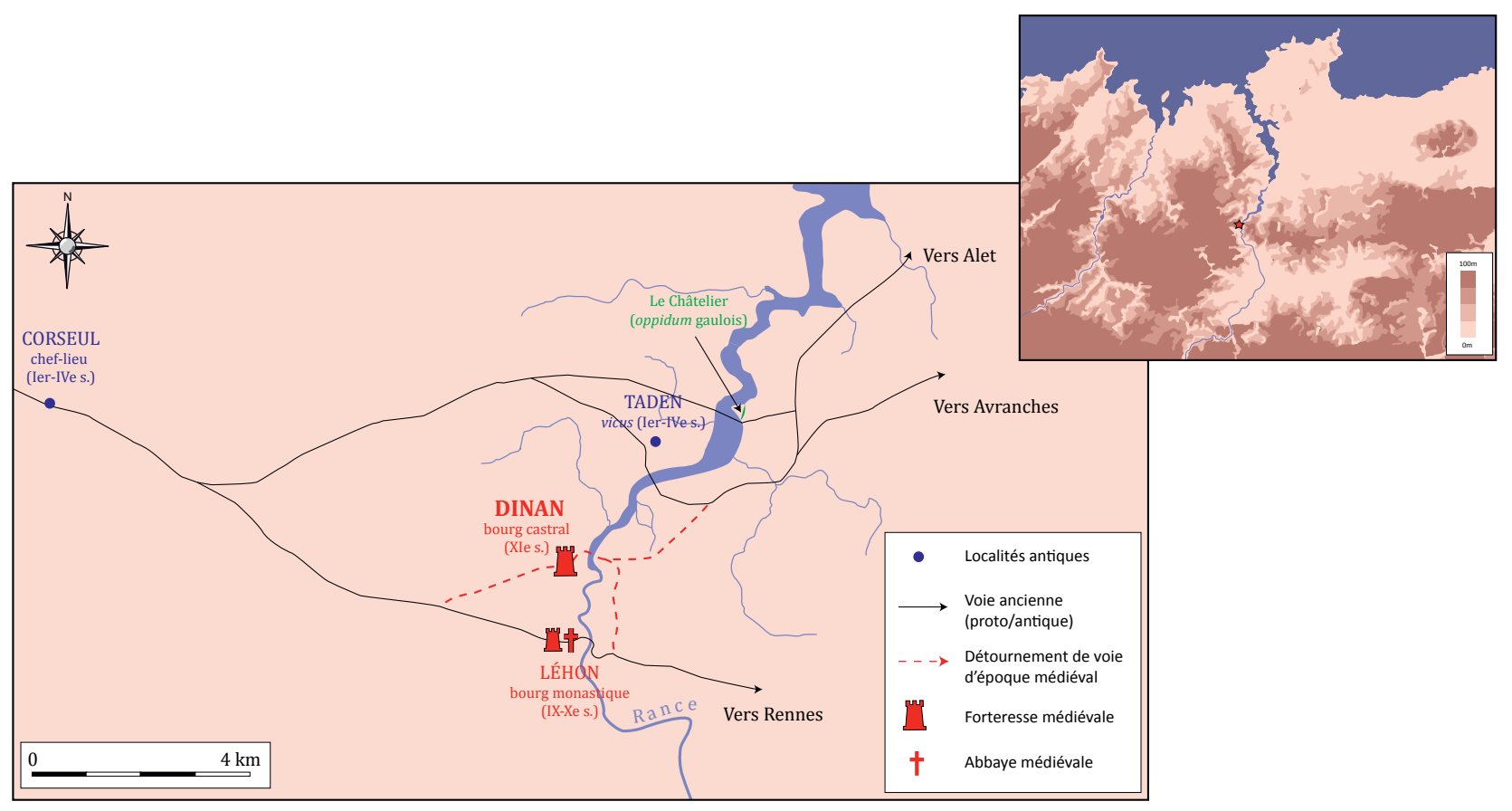

Figure 1 : Situation générale de Dinan dans son environnement naturel et archéologique.

Figure 1: General situation of Dinan in its natural and archaeological environment.

Dessin / Drawing : M. Dufeil

voies anciennes, une fois détournées, forment la base d'un nouveau réseau de communication, au carrefour des voies terrestres, fluviales et maritimes. Enfin, le flanc du plateau est creusé par un talweg abrupt et incurvé, par lequel il est possible de relier la rive du fleuve. Cette dépression le Jerzual - formera la première voie de pénétration vers la ville et constituera l'échine du bourg seigneurial. Elle dessine, en outre, les contours d'un puissant éperon destiné à accueillir la forteresse seigneuriale (fig. 2). À moins de $300 \mathrm{~m}$ au nord, sur le versant opposé, les restes d'une ancienne église surplombent le cours du fleuve. Si elle semble appartenir aux seigneurs de Dinan ${ }^{5}$, il est probable que sa fondation soit antérieure au milieu du $\mathrm{XI}^{\mathrm{e}} \mathrm{s}$. : outre la dédicace à saint Malo et la découverte, à proximité, d'un sarcophage ancien (Guigon, 1990), le parcellaire dessine les contours d'un enclos présumé, recoupé par l'embryon de bourg établi de part et d'autre de la rue Saint-Malo. Il est donc possible que le haut du plateau ait été occupé antérieurement à l'arrivée des seigneurs de Dinan.

L'agglomération de Dinan commence probablement à se développer dès les années 1040. Vers 1100, Geoffroy I ${ }^{\text {er }}$ de Dinan et son frère, Rivallon, favorisent l'installation d'un bourg monastique en rive droite du fleuve et en tête du pont qui le traverse, au pied du château (Dom

5. En 1108, l'église est offerte aux bénédictins de Marmoutier. Geoffroy ler de Dinan approuve la donation sur l'autel, ce qui tend à prouver que sa famille en était propriétaire jusqu'ici. Voir Barthélémy, Geslin de Bourgogne, t. IV, p. 390-392.
Morice, t. I, col. 439; Meazey, 1997, p. 32) ${ }^{6}$. Dans les années qui suivent, les seigneurs de Dinan encouragent l'établissement d'au moins deux autres bourgs, situés quant à eux sur le plateau occidental : les bourgs SaintSauveur et Sainte-Marie. Dès le début du XII ${ }^{\mathrm{e}}$ s., quatre bourgs monastiques gravitent autour de la forteresse seigneuriale, preuve s'il en est d'un développement rapide de l'agglomération (Bachelier, 2014, p. 214). Cet essor soutenu se traduit également sur le plan économique par l'émergence de nombreuses activités artisanales. Tandis que le tissu urbain gravit pas à pas la pente du Jerzual, l'épicentre économique se déporte vers les hauteurs du plateau, jusqu'à se fixer définitivement à l'ouest du noyau primitif. Ici, les textes du XIII ${ }^{\mathrm{e}} \mathrm{s}$. font mention d'un certain nombre de lieux et d'activités qui ont durablement marqué la toponymie de cette partie de la ville (Ibid., p. 218).

\section{Une première clôture?}

En 1123, les abbayes en charge des prieurés de SaintMalo et de Saint-Sauveur de Dinan concluent un accord définissant les limites topographiques des ressorts paroissiaux des deux églises. Il est ainsi convenu que la division paroissiale s'alignera sur celle récemment fixée lors du par-

6. D’après la Tapisserie de Bayeux, le château de Dinan existe en 1065, lors de la campagne bretonne de Guillaume le Conquérant. Pour un état des lieux plus détaillé, voir la contribution de J. Mesqui (Mesqui, 2017, p. 53-58). 


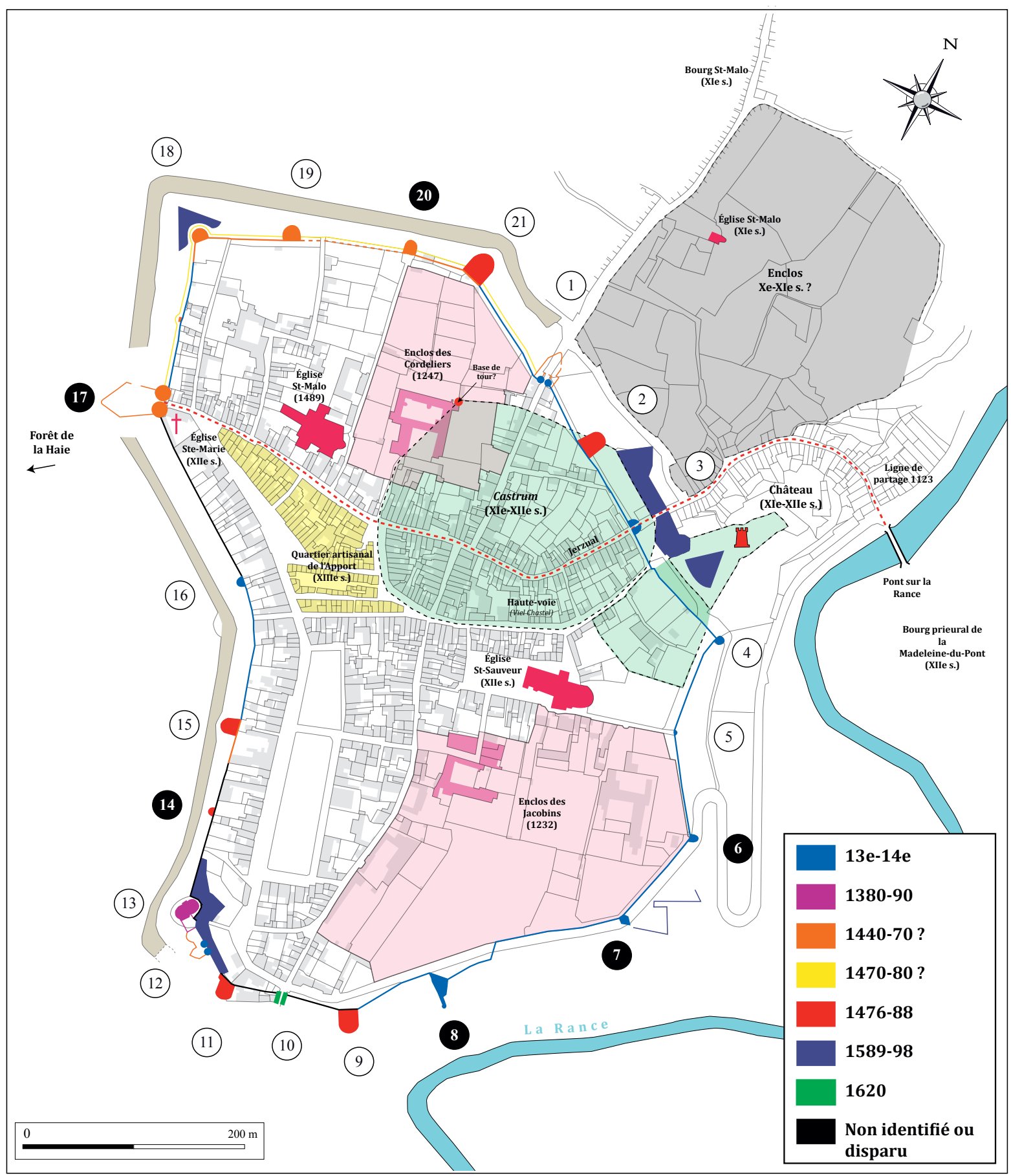

Figure 2 : Dinan, plan cadastral de 1843 interprété. Les ouvrages conservés sont numérotés en blanc, les ouvrages disparus ou ruinés en noir. Figure 2: Dinan, interpreted cadastral plan of 1843. The preserved works are numbered in white, the disappeared or ruined works in black.

1 : Porte Saint-Malo ; 2 : Tour du Gouverneur ; 3 : Porte du Jerzual ; 4 : Tour Sainte-Catherine ; 5 : Tour Cardinal ; 6 : Tourelle Sainte-Catherine ; 7 : Tour du BoisHarouard ; 8 : Tour Longue ; 9 : Tour Penthièvre ; 10 : Porte Saint-Louis ; 11 : Tour de Coëtquen ; 12 : Porte du Guichet ; 13 : Tour ducale ; 14 : Casemate (moineau d'artillerie) ; 15 : Tour du Connétable (ou tour du Poulailler, peut-être en référence au moineau voisin ?) ; 16 : Tour Beaufort; 17 : Porte de l'Hôtellerie ou de Brest ; 18 : Tour Saint-Julien ; 19 : Tour de Lesquen ; 20 : Tour de la Rue-Neuve ; 21 : Tour Beaumanoir.

1: Saint-Malo Gate, 2: Governor's Tower, 3: Jerzual Gate, 4: Sainte-Catherine Tower, 5: Cardinal Tower, 6: Sainte-Catherine Turret, 7: Bois-Harouard Tower, 8: Long Tower, 9: Penthièvre Tower, 10: Saint-Louis Gate, 11: Coëtquen Tower, 12: Guichet Gate, 13: Ducal Tower, 14: Casemate (caponier), 15: Constable Tower, 16: Beaufort Tower, 17: Hotel Gate or Brest Gate, 18: Saint-Julien Tower, 19: Lesquen Tower, 20: Rue neuve Tower, 21 : Beaumanoir Tower. 
tage de l'agglomération entre les fils de Geoffroy $\mathrm{I}^{\mathrm{er}}$, selon la ligne définie par l'artère principale (Barthélémy, Geslin de Bourgogne, t. IV, p. 396-398). Olivier II hérite de la partie nord de la ville et Alain ${ }^{\text {er }}$ de la partie sud, à l'exception du château, qui revient à son aîné. Le texte stipule néanmoins qu'une part du castellum est échue à Alain, ce qui sous-entend que le vocable est compris au sens large, probablement pour qualifier l'ensemble formé par le château et le bourg castral. Doit-on alors considérer que le bourg en question est également fortifié, au même titre que le château? Plusieurs indices le laissent entendre. Ainsi, l'acte de 1123 fait mention d'une porte située dans la rue " qui part de la tête du pont [...] pour aller jusqu’à la Haie ». De la même façon, vers 1150, le géographe arabe Al-Idrīsī décrit Dinan comme une agglomération ayant " tous les attributs d'une ville [et qui est] ceinte d'un mur en pierre " (Idrīsī, 1999, p. 419). Enfin, en 1198, on trouve mention des bourgeois de Dinan dans un texte stipulant que les moines du prieuré de la Madeleine-du-Pont ne peuvent accueillir sur leurs terres les bourgeois d'Olivier III, seigneur de la partie nord de Dinan (Dom Morice, t. I, col. 731). Au reste, dès la première moitié du XII ${ }^{\mathrm{e}} \mathrm{s}$., Dinan est le siège d'un archidiaconé et polarise un hôpital, quatre églises et une chapelle. Elle réunit donc suffisamment d'éléments de centralité pour mériter le rang de ville (Bachelier, 2014, p. 214). De façon plus probante, le parcellaire garde en mémoire les traces d'un enclos ovoïde délimitant, au nordest, un espace de 4 à 5 ha qui pourrait s'apparenter au premier castrum de Dinan (Ronsseray, 1986, p. 98 ; Mesqui, 2017, p. 58-60) [fig. 2]. D’après J. Mesqui, il est possible que cette clôture ait été d'emblée maçonnée. L'auteur se fie notamment au témoignage de l'abbé Le Giemble, rapportant la découverte, en 1886, d'une base de tour circulaire dans l'angle nord du couvent des Cordeliers (Le Giemble, p. 90-91). Sur le plan historique, cette première clôture est

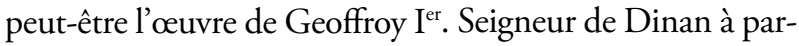
tir des années 1080, il se trouve souvent mêlé à quelques conflits armés et passe volontiers pour un homme belliqueux (Monier, 1977, p. 25; Morin, 2010, p. 120-122). En outre, il est le dernier de sa lignée à détenir seul le titre de seigneur de Dinan : après lui, ses descendants semblent se partager le titre de "dominus Dinanni », au sein de ce qui pourrait s'apparenter à une forme de coseigneurie (Dufeil, 2020b, p. 44-49).

\section{LES FORTIFICATIONS DUCALES :

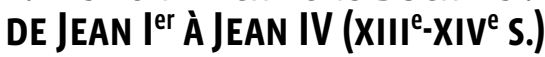

\section{L'enceinte de réunion : une construction ducale?}

En 1264, Alain d'Avaugour, seigneur de Dinan-sud et baillistre de son fils, Henri, pour la terre de Dinan-nord, vend l'intégralité de la ville à Pierre de Bretagne. L'année suivante, celui-ci la remet à son père, le duc Jean $\mathrm{I}^{\text {er }}$. Dès lors, Dinan rejoint le domaine ducal. Suite au décès d'Alain la même année, le jeune Henri est placé sous la tutelle de son grand-père, Henri II d'Avaugour. Dénonçant cette vente illégale - Alain n'avait pas le droit de disposer de la partie nord de Dinan, qui relevait de l'autorité de sa défunte épouse et devait donc revenir à leur fils -, le vieil Henri intente un procès au duc. L'affaire est portée devant le Parlement du roi de France et dure près de vingt ans, de 1265 à $1283^{7}$. Finalement, les droits du jeune Henri III d'Avaugour sur la partie nord de Dinan sont reconnus, bien qu'il lui faille encore les concéder en viager au duc. Lorsque Jean ${ }^{\text {er }}$ meurt, en 1286, Henri III récupère son fief comme prévu (Dom Morice, t. I, col. 1081). Il est généralement admis qu'une fois passé maitre de la ville, Jean $I^{\text {er }}$ finança la construction d'une nouvelle enceinte urbaine. Et pour cause, dans la mesure où ces défenses enserrent à la fois le nord et le sud de la ville, cela induit nécessairement que leur commanditaire ait été maître de l'ensemble, ce qui est effectivement le cas du duc, de 1265 à 1286, mais également d'Alain d'Avaugour, de 1255 à 1264. Vers 1257, Alain se joint à la révolte d'Olivier de Clisson contre Jean I ${ }^{\text {er }}$, qui en guise de représailles fait incendier la ville de Dinan (Dom Morice, t. I, col. 6, 976). Sur le plan contextuel, on peut donc concevoir qu'il ait été l'auteur d'une première campagne de travaux, d'autant que le lignage de Dinan occupe une place importante dans le réseau familial breton ${ }^{8}$. Ceci dit, en l'absence de données textuelles relatives à la construction de cette enceinte, il est difficile de se prononcer avec certitude. Seule l'étude architecturale et archéologique des ouvrages conservés est susceptible de fournir quelques indices.

\section{La morphologie générale de l'enceinte (fig. 2 et 3)}

Au XIII ${ }^{e}$ s., le centre névralgique de Dinan quitte le noyau primitif et se déplace plus à l'ouest, dans le quartier de l'Apport. En parallèle, la ville de Dinan accueille deux communautés de mendiants : les Dominicains et les Franciscains. Les premiers obtiennent la jouissance d'un vaste domaine jouxtant le bourg paroissial de SaintSauveur au sud; quant aux seconds, ils s'installent en bordure nord de l'artère principale. Dès 1250, l'extension

7. Le litige a laissé plusieurs traces écrites qui nous permettent de suivre l'évolution du conflit. Voir Lémeillat, 2014, n 163, p. 286; n²A, p. 313-314; nº 3A, p. 315-317; no 15A, p. 334-335; Dom Morice, t. I, col. 1050-51, 1066-67 ; Beugnot, 1839, p. 623624 et p. 670-671. On peut aussi se fier au travail de P. Meazey, qui a su démêler l'imbroglio relatif à cette affaire (Meazey, 1997, p. 131-139).

8. De 1175 à 1220, les seigneurs de Dinan-sud détiennent la charge de sénéchal de Bretagne. De plus, en 1197, Gervaise de Dinan épouse Juhel de Mayenne, autour duquel se développe un important réseau familial réunissant les lignages de Vitré, Fougères, Laval, Craon et Dol. 
topographique de Dinan est donc fixée et suit peu ou prou les contours du relief. Ces mêmes limites serviront après coup à définir une partie du tracé de la nouvelle enceinte de réunion. De plan polygonal, cette enceinte absorbe l'enclos antérieur, dont elle dépasse largement l'ampleur. Longue de $2650 \mathrm{~m}$, elle délimite une aire enclose de 31 ha. Sur toute sa moitié est, depuis la porte du Jerzual jusqu'à la tour Penthièvre, la muraille épouse les contours de l'abrupt et repose directement sur le rocher taillé en escarpe, dessinant une série de brisures caractéristiques des fortifications de relief. À l'ouest, entre la porte de l'Hôtellerie et la tour ducale, elle suit le rebord d'un vallon où s'écoule le ruisseau de Cocherel, qui prend sa source au nord de la ville close et va en s'approfondissant vers le sud, jusqu’à Léhon, où il rejoint la Rance. Enserrée par les deux cuvettes, la plateforme sur laquelle est bâtie la ville close est finalement étranglée au sud par un coude du fleuve, marquant ainsi la limite méridionale de l'enceinte. Enfin, sur tout le quart nord-ouest, depuis la porte de l'Hôtellerie jusqu'à la porte Saint-Malo, la muraille se développe librement face aux étendues marécageuses du plateau. À cet endroit, c'est la topographie urbaine qui semble avoir conditionné la définition du tracé, l'idée étant probablement d'enclore le quartier de l'Apport et le domaine des Franciscains.

\section{Des ouvrages caractéristiques de la fortification du XIII' $s$.}

Il est probable que le tracé de l'enceinte tel qu'on le connaît depuis la fin du XVII $s$ corresponde à celui défini dans le courant du XIII ${ }^{\mathrm{e}} \mathrm{s}$. En effet, sur la quinzaine d'ouvrages conservés à ce jour, au moins quatre d'entre eux présentent des traits caractéristiques de la fortification capétienne du XIII ${ }^{\mathrm{e}}$ s. (Hayot, 2015, Monographies, vol. 2, p. 596-599). Or, loin d'être bâtie sur le même flanc, chacune de ces constructions se trouve disséminée sur l'un des quatre fronts de l'enceinte : la porte Saint-Malo au nord, la tour-poterne Cardinal à l'est, la porte du Guichet au sud et la tour Beaufort à l'ouest (fig. 4). Il s'agit dans tous les cas de constructions modestes, d'un diamètre compris entre 6 et $7 \mathrm{~m}$, bâties sur un ou deux niveaux d'archères et dotées à la base d'un talus plus ou moins incliné, selon la proximité du socle rocheux. La mise en œuvre y est le plus souvent irrégulière et le couronnement, lorsqu'il est conservé, est constitué par une série de corbeaux à peine dégrossis, peut-être associés à l'origine à une galerie hourdée. Sauf exception (tour Beaufort), l'épaisseur des maçonneries est inférieure à $2 \mathrm{~m}$. Sur le plan défensif, chaque ouvrage applique les principes de commandement communs à la plupart des constructions capétiennes : le sommet des tours domine les courtines attenantes et les niveaux ne communiquent pas entre eux, de façon à limiter les possibilités d'intrusion ennemie. Enfin, chacune des tours est percée sur le front et sur les flancs par des archères à fente simple, quasi invariablement précédées d'une niche à destination du tireur. Seuls les flancs de la tour Cardinal sont équipés d'archères à ébrasement simple, la position de l'ouvrage dans un angle rentrant de la muraille ne lui permettant pas de bénéficier de la saillie nécessaire pour l'aménagement de niches de tir. D'un usage peu courant en Bretagne avant les années 1250, la présence systématique de l'archère à niche dans les ouvrages dinannais nous conduit à privilégier l'hypothèse d'une construction attribuable à la seconde moitié du XIII ${ }^{e}$ s. (Hayot, 2015, Synthèse vol. 2, p. 368). La physionomie des entrées de ville est elle aussi caractéristique des procédés mis en œuvre au XIII ${ }^{\mathrm{e}}$ s., sous l'influence de la sphère royale. Dans tous les cas, l'accès à la ville est placé sous la garde d'une combinaison assommoir-herse-

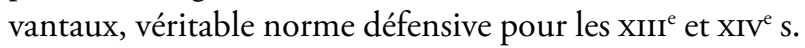
(Mesqui, 1991, p. 326). L'absence de franchissement du fossé solidaire de la construction corrobore également l'hypothèse de datation, la simple passerelle escamotable constituant la solution la plus privilégiée pour l'époque (Hayot, 2015, Synthèse vol. 2, p. 345). Enfin, à la porte Saint-Malo comme à la porte du Guichet, une niche évidée coiffe l'entrée vers la ville, plaidant ainsi en faveur d'une construction relativement avancée dans le siècle (Ibid., p. 339).

Hormis la tour Cardinal, certains ouvrages du front est pourraient également dater du XIII ${ }^{\mathrm{e}} \mathrm{s}$. ou du début du $\mathrm{XIV}^{\mathrm{e}}$ s. Selon la description offerte par l'ingénieur militaire Siméon Garengeau en 1693, la tourelle Sainte-Catherine, la tour Longue et celle du Bois-Harouard auraient un diamètre équivalent aux tours décrites plus haut, soit environ 6 m². La comparaison s'arrête là cependant, tant chacune d'entre elles présente des dispositions spécifiques. La tour du Bois-Harouard, par exemple, adopte un plan pentagonal à éperon qui rappelle certains ouvrages présents à la fin du XIII ${ }^{e}$ s. à Provins (Seine-et-Marne) ou Château-Thierry (Aisne) [Ibid., vol. 1, p. 270]. Malgré tout, les tours du front est partagent un point commun essentiel : elles sont presque toutes pourvues d'un niveau unique, disposé en partie supérieure de l'ouvrage. Ainsi, contrairement aux autres ouvrages dinannais, ces tours ne semblent pas directement conçues pour la défense active de la place, mais seulement pour la surveillance de la vallée. C'est d'ailleurs pour cette même raison que Garengeau observera plus tard que cette partie-ci de l'enceinte «n'est guère insultable ${ }^{10}$.

9. Archives départementales d'Ille-et-Vilaine (ADIV), C 492, GARENGEAu S., 1693, Estat des plus urgentes réparations à faire à la ville de Dinan en Bretagne pour la mettre hors d'insulte et empêcher un coup de main. 10. Ibid. 


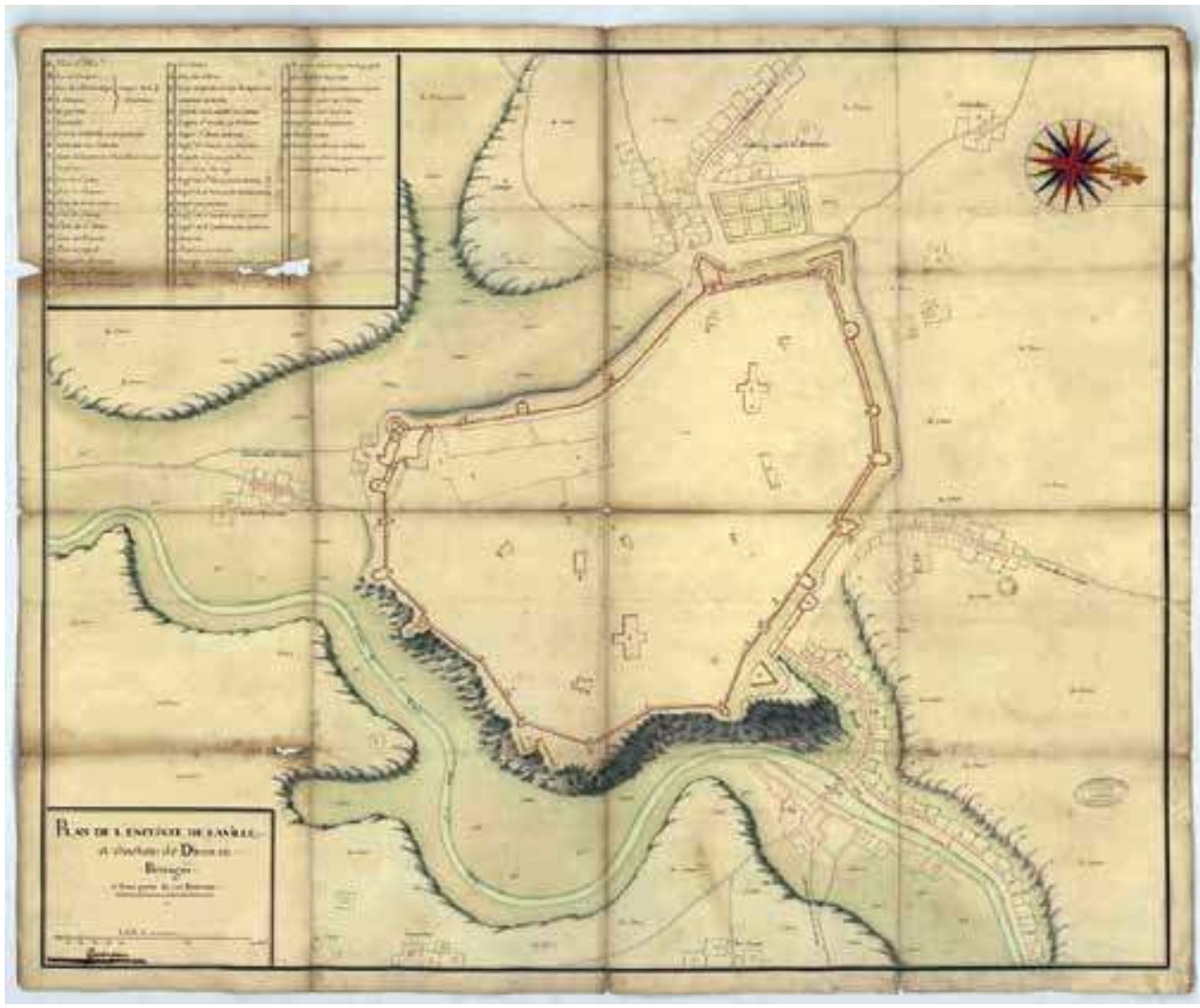

Figure 3 : Plan de Dinan relatif à l'état des réparations les plus urgentes à y faire, par S. Garengeau, 1693. (ADIV, (492).

Figure 3: Map of Dinan with the most urgent repair work by $S$. Garengeau, 1693. (ADIV, C 492).

\section{L'apport des textes: une enceinte mixte jusqu'au milieu du XIV ${ }^{e} s$. ?}

De 1342 à 1364, la ville de Dinan figure parmi l'un des principaux soutiens de Charles de Blois et Jeanne de Penthièvre dans le cadre du conflit successoral qui les oppose à Jean de Montfort. C'est à cette occasion que sont citées pour la première fois les nouvelles fortifications de Dinan. La scène se passe en 1364, peu après la victoire de Jean de Montfort fils sur Charles de Blois. Certaines villes ralliées au parti Blois-Penthièvre refusent alors de se rendre. Selon Froissart, c'est après être venu à bout d'un premier foyer de résistance à Jugon que Jean de Montfort et ses hommes se rendent à Dinan. "Là mist il grand siege et qui dura bien avant en l'ivier car la ville est forte et estoit adont bien garnie " (Froissart, L. I, t. III, p. 358). À l'octobre 1364, la ville de Dinan est donc suffisamment fortifiée pour soutenir un siège d'un mois, qu'elle décidera elle-même de lever. Au début du conflit pourtant, elle ne semble guère imprenable. Pour l'année 1342, Froissart dit à propos de Dinan qu'elle " n'étoit fermée, fors de fossés et de palis " (Ibid., t. I, p. 151). La même année, Édouard III d'Angleterre met pied en Bretagne et prend la tête d'une expédition ayant vocation à récupérer les principales villes bretonnes pour le compte de Jean de Montfort. D'après Froissart, il se rend à Dinan. Ici, il « regarda qu'elle étoit bien prenable, car elle n'étoit fermée que de palis» (Ibid., p. 175). Deux ans plus tard, en 1344, Charles de Blois relate le pillage dont souffrit la ville " au temps que le roy Dengleterre fut en Bretaigne " (Jones, 1996, nº 38, p. 85-86). À cette occasion notamment, on apprend que les Anglais ont dérobé une partie des trésors de l'église Saint-Sauveur, ce qui prouve qu'ils ont pénétré dans la ville.

Ainsi, si l'on en croit les textes, la ville de Dinan termine de se fortifier entre 1342 et 1364 . Jusqu'à cette date, il est donc possible que les défenses de Dinan aient été mixtes, et que seules les portes et certaines tours de l'enceinte aient été bâties en dur. À propos du siège de 1342 notamment, Froissart rapporte que les Anglais « coupoient les palis, et en bref temps grandement les endommagèrent, et tant qu'ils en jetèrent un grand pan par terre, et entrèrent dedans [la ville de Dinan] efforcément ", suggérant l'existence de palissades en bois. Cela dit, rien n'interdit une définition plus étendue du terme "palis», qui peut définir de simples points faibles dans la défense, voire des parties en cours de travaux, des réparations, etc. En se basant sur un acte daté de 1366 relatif à l'amortissement des terres " toutes sises dedans les murs et clostures de la ville [de Dinan] ", S. Gesret envisage la persistance d'une enceinte mixte jusqu'à une date plus tardive encore (Gesret, 1998, p. 30 ; Jones, $1980, \mathrm{n}^{\circ} 71$, p. 124-125). Sans contredire cette hypothèse, on se demande si le terme de "clostures " ne pourrait pas simplement renvoyer à quelques défenses 


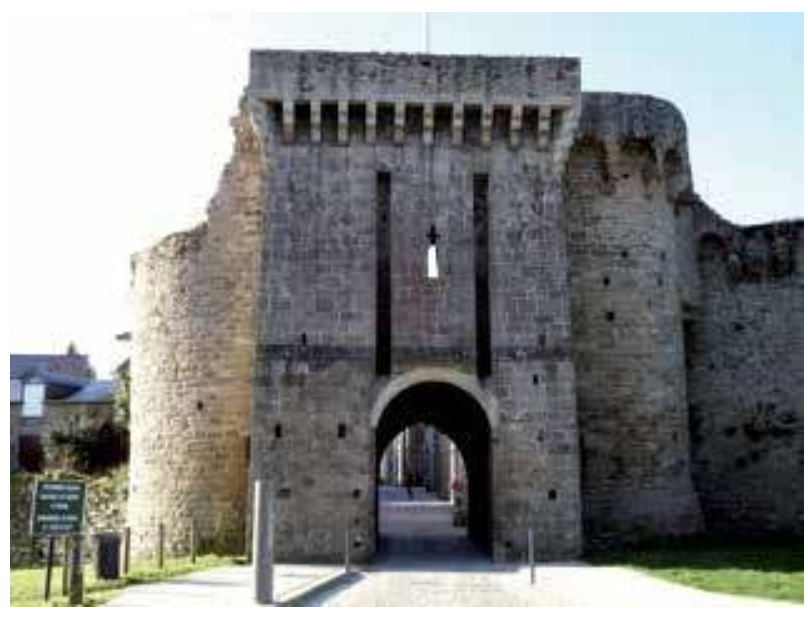

Figure 4 : Vue générale de la porte Saint-Malo, à Dinan.

Figure 4: View of Saint-Malo Gate in Dinan.

Cliché / Picture : M. Dufeil

mises en œuvre temporairement, à l'image des palissades recouvertes de peaux signalées en avant de l'enceinte urbaine de Nantes, en 1348 (Dreillard, 2017, p. 337).

\section{La confrontation des données : une reprise des travaux de fortification sous Charles de Blois?}

En accord avec les données textuelles, certains indices tendent à prouver que la construction de courtines maçonnées à Dinan n'interviendrait pas avant la première moitié du XIV ${ }^{e}$ s. À première vue, les murailles les plus anciennes semblent concentrées sur le quart nord-est, depuis la tour Beaumanoir jusqu'aux abords de l'ancienne tourelle Sainte-Catherine. Ces courtines sont le plus souvent signalées par l'emploi de consoles frustes, faites d'un simple empilement de blocs équarris. Leur épaisseur moyenne se situe autour de $2,50 \mathrm{~m}$, soit à peu près autant que les épaisseurs de mur relevées à la porte du Jerzual ou à la tour Sainte-Catherine, mais bien davantage que celles observées à la porte Saint-Malo et à la tour Cardinal. Plus massives encore, les courtines enserrant la porte du Jerzual mesurent près de $3,50 \mathrm{~m}$, sans doublement visible des maçonneries. L'importance des épaisseurs de mur et l'existence d'un couronnement en dur paraissent donc plutôt indiquer la première moitié du XIv $\mathrm{e}$. que la seconde moitié du XIII s. (Amiot, 1999, p. 423-426).

La tour Sainte-Catherine et la porte du Jerzual pourraient, elles aussi, dater de la première moitié du XIV s., en tout cas dans leur état présent. Il est possible en effet que la tour-porte du Jerzual remplace et complète un précédent ouvrage, en partie conservé dans la construction actuelle (fig. 5). Plusieurs fentes d'archère ajourant les flancs du passage d'entrée suggèrent l'existence d'un premier niveau, pour lequel il ne subsiste plus aucun accès.
Joints aux quelques reprises discernables dans les maçonneries du passage, ces indices permettent de formuler l'hypothèse d'une porte antérieure, enchappée après coup dans une imposante tour-porte. Si elle est avérée, cette transformation interviendrait nécessairement avant la diffusion du système de pont-levis à flèches, dans les années 1360-1370. En effet, la porte du Jerzual a cela de notable qu'elle constitue un exemple d'adaptation à l'usage de ce type de franchissement, marqué ici par le bûchement de l'arc d'entrée et l'insertion de corbeaux saillants destinés à supporter l'axe du balancier.

En l'état, la confrontation des données documentaires et matérielles permet par conséquent d'envisager une reprise, ou du moins une accélération des travaux de fortification sous le commandement de Charles de Blois, entre 1342 et 1364. A priori, cela n'a rien d'étonnant: nous savons que Charles de Blois a coutume d'accorder des avantages substantiels aux communautés qui le soutiennent, notamment celui de lever des impôts exceptionnels pour l'entretien des défenses. Or, Dinan compte parmi ses meilleurs soutiens. On en veut pour preuve la participation des bourgeois de Dinan à une assemblée réunissant - à Dinan, en 1352 - une part des nobles, prélats et représentants des villes favorables aux Blois-Penthièvre (Dom Morice, t. I, col. 1486). C'est en 1340 également qu'apparaît pour la première fois la charge de capitaine de Dinan, dont la mission consiste, entre autres, à diriger les travaux de défense (Monier, 1977, p. 281; Leguay, 1981, p. 29). Il est donc possible que la ville close de Dinan ait été définitivement revêtue de murailles en pierre à l'occasion du conflit successoral opposant les prétendants à la couronne ducale. Certains des ouvrages antérieurs ont pu être repris au même moment, à l'image de la porte du Guichet, surélevée d'un niveau (fig. 6). Enfin, passé l'épisode de la guerre de Succession, les murailles sont à nouveau citées à l'occasion de la construction de l'imposante tour-résidence du duc Jean IV, à l'angle sud-ouest de la ville, dans les années 1380-1390 (Mesqui, 2017, p. 60-80).

\section{LES FORTIFICATIONS DUCALES : DE FrançoIs II À FrançOIS II (1442-1488)}

\section{Quelques éléments de contexte}

Si la guerre de Succession de Bretagne oppose au premier plan deux importants lignages bretons, elle est également le théâtre indirect et épisodique d'un conflit endémique opposant plus largement les royaumes de France et d'Angleterre. Prise entre deux feux, à la confluence des ambitions françaises et anglaises, la Bretagne devait par conséquent faire l'objet d'importants travaux de fortification. Jusqu'au milieu du $\mathrm{Xv}^{\mathrm{e}} \mathrm{s}$. pourtant, elle bénéficie de 


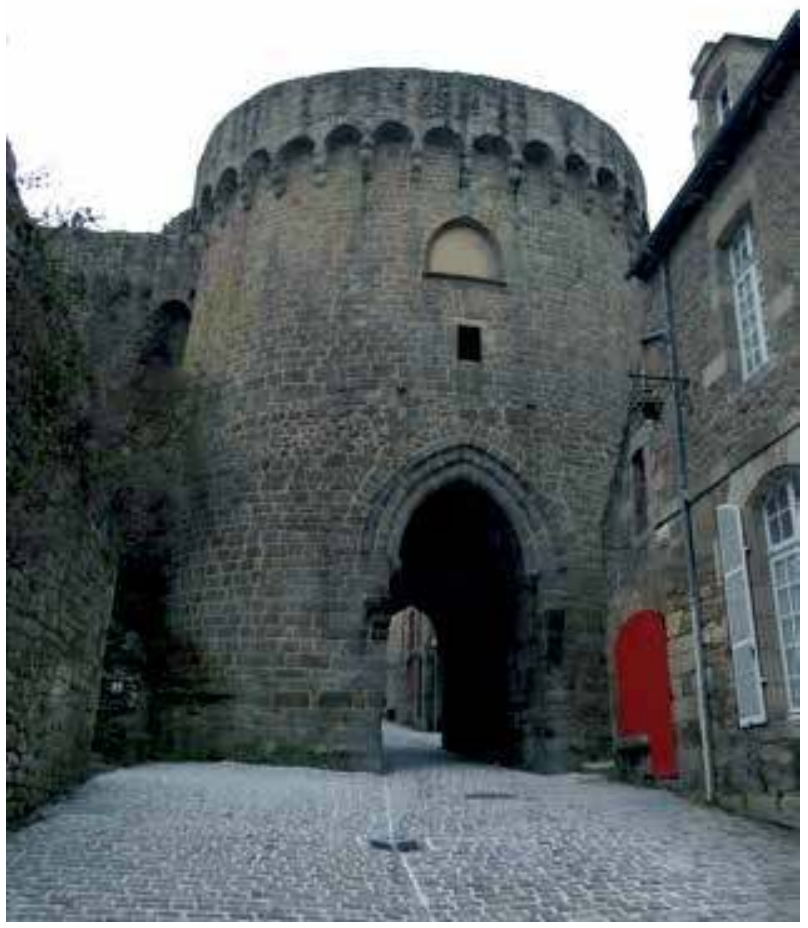

Figure 5 : Vue générale de la tour-porte du Jerzual, à Dinan.

Figure 5: View of Jerzual Gate in Dinan.

la politique de "neutralité opportuniste " pratiquée par le duc Jean $\mathrm{V}$, qui tire parti des difficultés du voisin français pour affermir l'autonomie de son duché (Leguay et Martin, 1982, p. 194). Conscient de la fragilité d'un tel équilibre, le duc n'en néglige pas moins l'entretien des défenses. C'est pourquoi la plupart des villes fortifiées de Bretagne accueillent dès cette époque d'immenses chantiers urbains, dont le financement est le plus souvent laissé à l'initiative des villes. Dans un premier temps, il s'agit surtout d'agrandir le périmètre de la ville close en y intégrant les faubourgs périphériques, comme c'est le cas à Rennes. Le plus souvent néanmoins, c'est l'annonce d'un nouveau péril qui motive ces travaux. En 1442 en effet, François I ${ }^{\text {er }}$ succède à Jean $\mathrm{V}$ et met fin à la neutralité bretonne. En rejoignant le parti français, le duché s'expose à la menace anglaise.

Sur le plan militaire, la guerre de Cent Ans marque également l'apparition et le développement de l'artillerie à poudre en Europe. Cité dans les textes dès la fin des années 1330, l'usage du canon se répand lentement. En effet, loin d'être une révolution, le recours efficace à cette nouvelle arme requiert un certain nombre de tâtonnements, tant pour les assiégeants que pour les assiégés

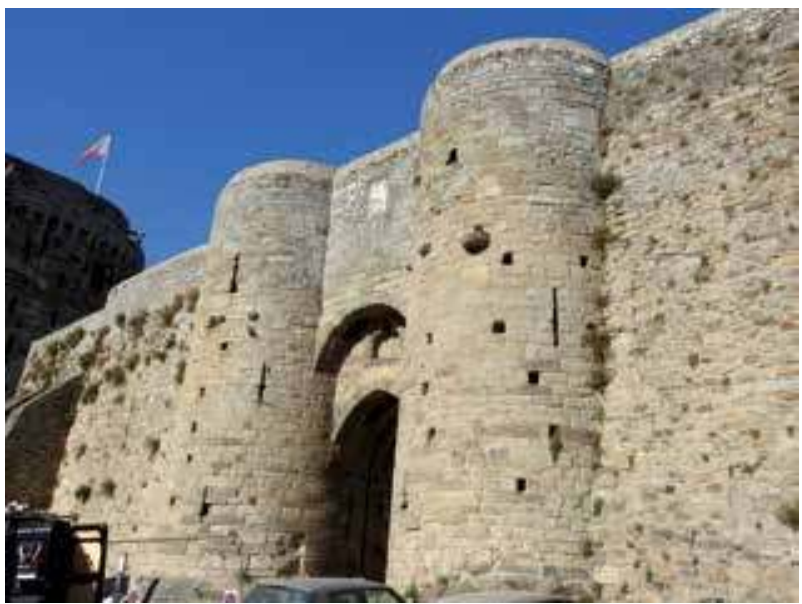

Figure 6 : Vue générale de la porte du Guichet, à Dinan.

Figure 6: View of the Guichet Gate in Dinan.

Cliché / Picture : M. Dufeil

(Crouy-Chanel, 2020, p. 314-319). À partir des années 1460 finalement, l'essor technologique entraîne une modification rapide de l'art du siège : plus précis, plus fréquents et plus puissants, les tirs offensifs sont désormais orientés vers les embrasures de tir et les couronnements, quand ceux des défenseurs bénéficient d'un plan de feu élargi (Ibid., p. 342-344). Les assiégés adaptent ainsi leurs défenses : la hauteur des ouvrages diminue, les murs et parapets s'épaississent, les mâchicoulis et crénelages, trop fragiles, tendent à disparaître... Bref, l'ouvrage s'épure et se compacte.

\section{Une ville « encore indigente de fortifications »}

À Dinan, le premier quart du $\mathrm{Xv}^{\mathrm{e}}$ s. voit se développer un embryon d'administration civile. Les textes signalent l'existence d'un conseil de notables décidant de la levée des impôts et des travaux à réaliser dans la ville et ses abords (Monier, 1977, p. 446). Parmi les bourgeois présents au sein de cette assemblée figure un « miseur de la réparation » chargé de la tenue des comptes municipaux et de la direction des grands travaux civils et militaires sous la surveillance d'un " conterolle des œuvres et réparacions ", cité en $1457^{11}$. Malheureusement, l'ensemble de ces comptes semble avoir rapidement disparu : en 1460 déjà, on déplore qu'ils soient gardés chez un certain Jehan May (Leguay, 1986, p. 52) ${ }^{12}$. Aussi n'est-il guère possible de suivre le détail des importants travaux de fortification

11. Archives départementales de Loire-Atlantique (ADLA), registres de la Chancellerie de Bretagne, B03, fo 69 .

12. L'inventaire de l'artillerie de 1495 mentionne l'existence d'une « tour Jehan May ", ce qui renforce l'hypothèse d'une phase de renforcement dès les années 1450-60. Voir ADLA, Trésor des Chartes des Ducs de Bretagne, E216-13, Inventaire des engins de guerre existant dans les places de Rennes, de Vitré, de Fougères, de 
qui, ici comme ailleurs, transforment le paysage urbain. En 1464, il est dit que la ville est « encore indigente de fortifications en plusieurs endroits $»^{13}$. Sans doute cette indigence tient-elle plus à l'obsolescence des défenses qu'à une réelle carence dans le tracé de l'enceinte. Par ailleurs, à partir des années 1460 , certains écrits comptables suggèrent l'existence de travaux de fortification. Parmi les privilèges concédés par le duc, les édiles locaux bénéficient du droit de lever des taxes spéciales sur les marchandises vendues dans l'enceinte de la ville. La plupart du temps, ces octrois servent à l'entretien des fortifications urbaines (Leguay, 1981, p. 145). Selon les circonstances, le montant des taxes est donc amené à évoluer, en particulier lorsqu'un conflit menace. Ainsi, en 1464-1465, de nouvelles taxes sur les boissons apparaissent. Sous le nom de " cinquaign ", « dizain ", " vingtain " ou " trantin ", il s'agit dans tous les cas de taxes pesant sur la vente de vin, en plus du billot traditionnel. Pour l'année 1464, le duc octroie aux bourgeois de Dinan un " trantin sou ", soit le droit de lever 30 sous par pipe de vin étranger vendue dans l'enceinte de la cité (Ibid., p. 93). Ce droit est renouvelé quelques années plus tard, en 1469. Au même moment, on mobilise cent archers et arbalétriers pour la défense de la ville (Gesret, 1998, p. 32). Les années 14501460 marquent-elles le point de départ d'une nouvelle campagne de travaux? Sur le plan architectural du moins, certains ouvrages semblent pouvoir être attribués à cette même période.

\section{Un premier effort de modernisation au temps de François er $^{\text {er }}$ Pierre II?}

Secteur le plus exposé, car établi face au plateau, le quart nord-ouest de l'enceinte paraît faire le premier l'objet de travaux de modernisation. Une nouvelle porte, dite " de l'Hôtellerie ", est ainsi bâtie à l'ouest de la ville, probablement en remplacement d'un précédent ouvrage (fig. 7). Sur le plan morphologique, cette entrée de ville est caractéristique des châtelets monumentaux à double entrée piéton-charroi, bien représentés en Bretagne. Il en existe plusieurs exemples de conservés, dont la porte Broërec à Hennebont, les tours Paradis à Brest ou encore les portes Mordelaises à Rennes, toutes bâties dans le courant du Xve s. Dans l'ensemble d'ailleurs, les dispositions générales de la porte de l'Hôtellerie sont assez proches $\mathrm{du}$ cas rennais, mais l'importance des réaménagements mis en évidence à cet endroit limite la pertinence des comparaisons (Esnault, 2014, p. 58-65). De plus, il faut noter que la persistance de ce type d'entrée ne permet pas réel-

Dol, de Saint-Malo, de Dinan, de Morlaix, de Brest, de Quimper, de Conq, de Vannes, d'Auray, d'Hennebond, du Croisic, de Guérande, de Redon et de Nantes. 13. Ibid., fos $175-176$. lement de resserrer l'hypothèse de datation au-delà du seul $\mathrm{Xv}^{\mathrm{e}}$ s. Seule la forme des canonnières - une niche ouverte et ébrasée aboutissant sur un orifice circulaire à cran de mire solidaire ménagé dans l'allège des fenêtres pour un canon posé au sol - pourrait éventuellement témoigner en faveur des années 1440-1450, mais sans réelle certitude.

Au nord, trois tours à canon sont également bâties de façon à protéger le quart nord-ouest. Suivant les données recueillies dans les sources et les observations réalisées in situ, il est possible d'établir certains parallèles entre ces ouvrages, dont la morphologie générale est proche. Plus massive et mieux appareillée, la tour de Lesquen pourrait néanmoins être postérieure aux deux autres (fig. 8). Dans ce cas-ci en effet, la saillie en avant des courtines augmente, tendant légèrement vers le fer à cheval, et les murs s'épaississent, jusqu'à atteindre $5 \mathrm{~m}$ au front, contre seulement $3,90 \mathrm{~m}$ à la tour Saint-Julien. En outre, contrairement à la porte de l'Hôtellerie, dont les orifices de tir sont encore parfois associés à une fente haute pour l'usage de l'arme à feu et de l'arme de jet, la tour de Lesquen ne parait avoir été dotée que de simples canonnières à fente courte, pour l'usage privilégié du canon posé au sol. Le plan de feu semble lui aussi évoluer et un soin plus attentif est porté aux tirs rasants, avec la mise en place d'un premier niveau disposé en fond de fossé. À titre de comparaison, les tours dinannaises entretiennent de nombreux points communs avec celles mises au jour au château de Guingamp, dont la construction remonterait aux années 1440 (Beuchet, 2014). À Dinan comme à Guingamp, les fonctions d'habitat et de défense coexistent de façon hiérarchisée au sein du même ouvrage, et le premier niveau est souvent relégué à la défense des fossés, par l'intermédiaire de casemates voûtées pour la seule arme à feu. D'une forteresse à l'autre, on retrouve également les mêmes caractéristiques morphologiques ou typologiques : diamètre des tours, épaisseur de mur, couvrements planchéiés, modénature et configuration des baies, etc. Plus proches de la sphère dinannaise, les ruines du château de Coëtquen offrent d'autres éléments de comparaison, là aussi datés par les textes des années 1440 (Blanchard, 1894, t. IV, p. 262-263). On notera par ailleurs que les commanditaires des deux forteresses entretiennent un lien étroit avec la ville de Dinan : le premier accède au trône ducal en 1450 sous le nom de Pierre II et réside occasionnellement dans la ville jusqu'à sa mort, en 1457; quant au second, Raoul V de Coëtquen, on le trouve cité au même moment au rang de capitaine de Dol, Dinan et Léhon (Monier, 1977, p. 282). Les deux personnages ont donc potentiellement joué un rôle dans la mise en défense de la ville, en particulier Raoul qui, en qualité de capitaine, dut piloter les travaux de fortification. Décédé au plus 


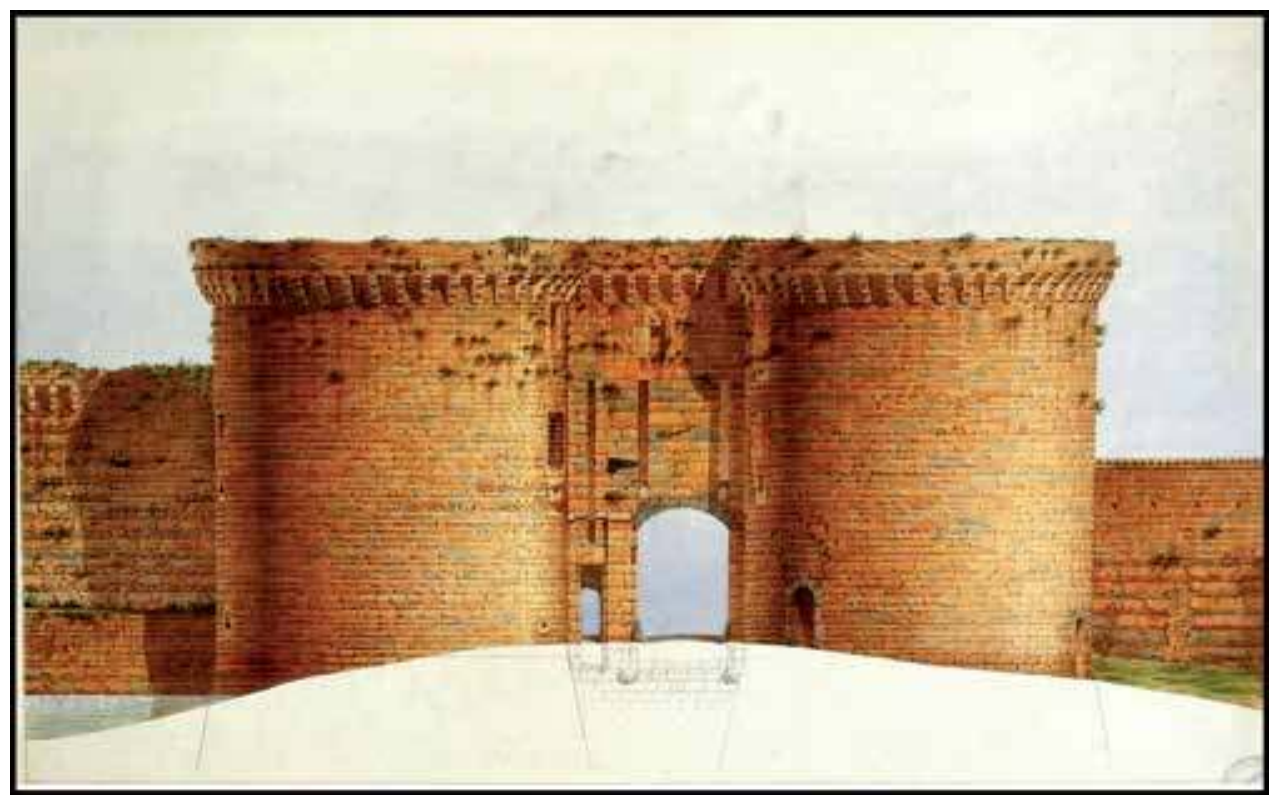

Figure 7 : Vue générale de la porte de l'Hôtellerie de Dinan par Édouard Corroyer, en 1872. L'architecte a également réalisé des relevés en coupe et en plan, laissant voir le détail des aménagements intérieurs.

Figure 7: View of the Hotel Gate in Dinan by Edouard Corroyer, in 1872. The architect also produced cross-sectional and plan drawings, showing details of the interior fittings.

Médiathèque de l'architecture et du patrimoine, 0082/022/1001

tard en $1452^{14}$, il est remplacé par Michel de Rieux, luimême déchargé de la capitainerie en 1457, au profit de Robert de Rosnyvinen, qui remplit cet office jusqu'à son décès, en 1476 (Dom Morice, t. II, col. 1710 ; Ibid., t. III, col. 323).

En somme, la confrontation des sources documentaires et matérielles suggère l'existence d'une première phase de travaux, débutant peut-être à l'ouest avec la porte de l'Hôtellerie et s'achevant au nord avec la tour de Lesquen. La comparaison avec des ouvrages plus connus permet de rattacher ces tours aux ouvrages de seconde génération mis en évidence par Jocelyn Martineau dans son travail de classification des tours à canon bretonnes (Martineau, 2011, p. 210-211). Aussi proposons-nous d'attribuer cette première série d'ouvrages aux années 1440-1470, correspondant essentiellement aux règnes des ducs François I ${ }^{\text {er }}$, Pierre II et au commencement du règne de François II. Un examen plus attentif des élévations conservées serait toutefois nécessaire pour mieux renseigner la chronologie de cette partie-ci de l'enceinte. Le dégagement des tours de Lesquen et Saint-Julien, partiellement ou entièrement comblées depuis l'intérieur, permettrait notamment de compléter la reconnaissance du dispositif défensif mis en œuvre dans ces tours de flanquement, pour ainsi mieux les dater. Enfin, la comparaison avec d'autres ouvrages connus - Guérande ou Nantes pour les années 1450-1460 (Martineau, 2011, p. 197-199; Martineau, 2016a) - apporterait quelques éléments nécessaires pour une contextualisation plus large, à l'échelle du duché de Bretagne.

14. En 1452, Jean, fils de Raoul, est qualifié de « sire de Coëtquen », alors qu'il n'était que «Jehan de Coesquen » quelques années plus tôt (Dom Morice, t. II, col. 1372, 1627).

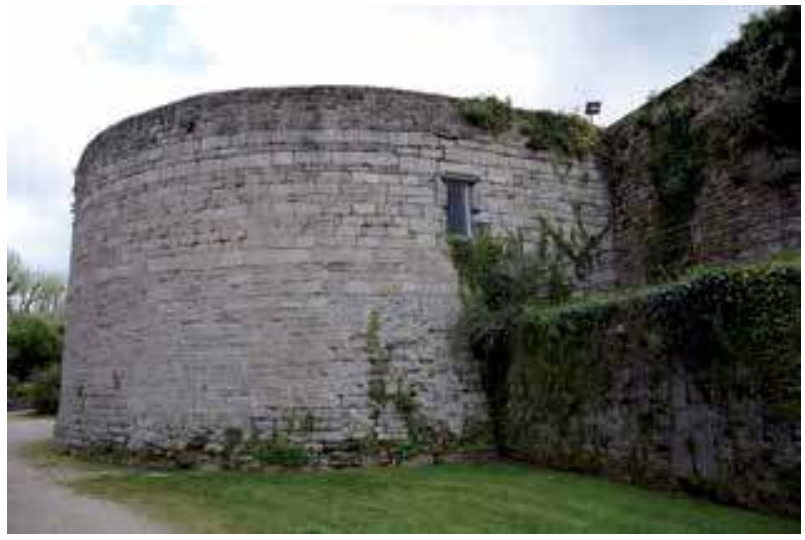

Figure 8 : Vue générale de la tour de Lesquen, à Dinan.

Figure 8: View of the Lesquen Tower, in Dinan.

Cliché / Picture : M. Dufeil

\section{L'accélération des travaux de fortification sous François II}

Sous le gouvernement du duc François II, les travaux de fortification s'intensifient partout en Bretagne. Tandis que le conflit franco-anglais s'achève, l'arrivée de Louis XI à la tête du royaume tend à envenimer les relations franco-bretonnes. Roi autoritaire, le nouveau souverain est bien décidé à mettre fin à la mollesse des vieux liens de vassalité unissant le duché breton au royaume de France pour leur substituer un rapport de sujétion plus strict (Leguay et Martin, 1982, p. 392-393). Peu enclin à se reconnaître sujet du roi de France, François II décide de préparer son duché à un conflit qu'il sait inéluctable. En 1465, il rejoint la Ligue du Bien public - une coalition de grands feudataires s'érigeant contre l'autorité 
royale, en partie menée par l'héritier du puissant duché de Bourgogne. D'intrigues en escarmouches, le camp des coalisés s'amenuise cependant : en 1477 , le problème bourguignon est en passe d'être réglé; reste alors la Bretagne de François II, dernière poche de résistance (Ibid., p. 397-398).

À partir de 1476, plusieurs mandements ducaux font explicitement état de travaux supplémentaires pour la mise en sûreté de la ville de Dinan. Au début de l'année, François II déclare " quil est de necessite fortiffier et emparer nostre ville de Dinan qui est assise en frontiere, tant de clostures, douves et foussez que autres choses ${ }^{15}$. En conséquence, il ordonne la réquisition contrainte et forcée des habitants d'une soixantaine de paroisses avoisinantes pour faire ouvre " de besche, portaige et vuidange des terres et matières des douves et foussez ". L'année suivante, il étend l'ordre de réquisition des paroissiens jusqu'au terroir de Saint-Brieuc et requiert la présence supplémentaire d'une main-d'œuvre spécialisée - les Lamballais - (Monier, 1977, p. 173-174). Selon toute vraisemblance, la masse des ouvriers mobilisés dut essentiellement servir à l'élargissement considérable des douves - jusqu'à $45 \mathrm{~m}$ en certains points - et à l'érection, grâce aux terres ainsi extraites, d'un long talus de contrescarpe s'étendant depuis la tour Penthièvre jusqu'aux abords de la porte du Jerzual, soit d'un rebord à l'autre du plateau ${ }^{16}$. En accord avec ces décisions, plusieurs documents comptables rendent compte là aussi de l'ampleur des travaux. À partir de 1476 en effet, les octrois concédés aux bourgeois s'accélèrent (Monier, 1977, p. 169; Gesret, 1998, p. 33). Plus encore, en 1477, le duc décide de la levée d'un impôt exceptionnel récolté " de quinze jours en quinze jours " pour procéder au paiement des ouvriers spécialisés employés sur le chantier, lequel impôt aura cours " jusques a perfection dudit ouvrage " (Monier, 1977, p. 174). Outre ces multiples privilèges fiscaux, le duc accorde quelques aides ponctuelles à la Ville de Dinan. Ainsi, en 1481-1482, les bourgeois de Dinan reçoivent une somme de 800 livres; puis, en 1485 , le duc demande aux miseurs de Rennes de verser 1000 livres à ceux de Dinan pour aider au financement des travaux de fortification. Toutes ces concessions prouvent l'ampleur considérable des travaux entrepris à Dinan durant ces mêmes années.

15. ADLA, registres de la Chancellerie de Bretagne, B08, $f^{\circ} 44-44 \mathrm{~V}^{\circ}$. Transcris par Monier, 1977, P. 165-166

16. À propos des vocables « douves » et « foussez », un traité d’usages locaux rappelle que « par l'expression fossés, on entend chez nous les clôtures en terre, ou dont les parements seuls sont en pierre. [...] Le mot douve indique vulgairement le creux pratiqué au pied du fossé. [...] C'est, en un mot, l'endroit d'où l'on extrait les terres pour l'édification du fossé, ou pour le réparer. » (Limon, 1852, p. 104). Les grandes tours à canon de Dinan : une synthèse
de la fortification bretonne des années 1476-1488

En parallèle aux travaux de terrassement, la menace d'une guerre imminente paraît avoir motivé la construction de cinq grandes tours à canon défendant au sud, à l'ouest et au nord la ville close de Dinan. Sans doute bâtis dans un court laps de temps, ces ouvrages forment un ensemble tout à fait exceptionnel, aussi riche que varié. En effet, si elles partagent certains standards défensifs, chacune de ces tours n'en possède pas moins des caractéristiques propres, variables d'une construction à l'autre, de sorte qu'elles représentent, une fois réunies, une synthèse de la fortification bretonne des années 1470-1480. Il est ainsi possible de proposer une chronologie relative d'évolution de ces tours, en s'appuyant essentiellement sur des marqueurs d'ordre technologique et morphologique, tels que l'épaisseur des maçonneries, la fonctionnalité des espaces, la nature du plan de feu ou encore la forme des embrasures de tir.

De façon générale, cette seconde phase de renforcement est marquée par un effort de standardisation accru, de plus en plus perceptible à mesure que le chantier avance. À l'extérieur, le tracé semi-circulaire s'efface complètement devant le plan en fer à cheval, nettement plus allongé. Les ouvrages adoptent désormais un profil trapu et saillant, offrant à l'assaillant un front épais et aveugle, capable de résister aux tirs en brèche (fig. 9). À l'intérieur, la coexistence des fonctions d'habitat et de défense atteint sa plus haute expression : l'usage du canon est dorénavant relégué aux casemates cloisonnées qui sont ménagées à tous les niveaux dans les flancs de la construction, limitant de cette façon la circulation des fumées toxiques. Bien souvent même, la gorge de l'ouvrage est percée d'une ou deux baies pour la ventilation du corps de résidence. À mesure que le chantier progresse, l'aspect défensif prend néanmoins le pas. Tandis que les tours Penthièvre, de Coëtquen et du Connétable sont invariablement bâties sur trois niveaux voûtés, les tours du Gouverneur et Beaumanoir n'en comprennent plus que deux. Chez l'une comme chez l'autre, la moitié supérieure de l'ouvrage est laissée pleine et aveugle, de façon à opposer une bonne résistance aux vibrations causées par l'usage d'armes lourdes disposées sur le haut des tours. Moins élevées, ces tours sont par là même plus ramassées, opposant à l'assaillant des murs solides, atteignant 7 à $8 \mathrm{~m}$ d'épaisseur sur les flancs et jusqu’à 7,50 m sur le front, contre $5,90 \mathrm{~m}$ en moyenne pour les ouvrages antérieurs. Cela est encore plus vrai à la tour Beaumanoir, qui est de loin l'ouvrage le plus imposant (fig. 10). Outre ses dimensions exceptionnelles, proches de réalisations plus tardives, cette tour se démarque par l'absence de couvrement, et plus 


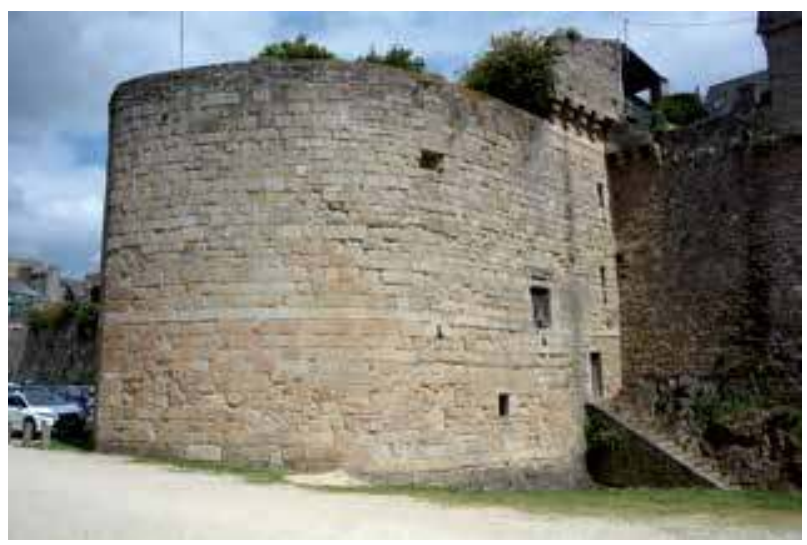

Figure 9 : Vue générale de la tour du Connétable, à Dinan. Cette tour est dotée d'un front en amande censé dévier les projectiles ennemis.

Figure g: View of the Constable Tower in Dinan. This tower has an almondshaped front that is supposed to deflect enemy projectiles.

Cliché / Picture : M. Dufeil

largement du moindre élément de confort. Il s'agit donc d'un ouvrage purement défensif, qui contraste résolument avec la tradition des tours mixtes jusque-là privilégiée. Enfin, on notera que les tours Penthièvre, de Coëtquen et du Connétable sont frappées aux armes de Jean II de Coëtquen, fils de Raoul V, et comme lui capitaine de Dinan, de 1477 à 1488 (Dom Morice, t. II, col. 323; Bouchart, fo 236). Également nommé au rang de grand maître de l'hôtel ducal, Jean de Coëtquen est secondé sur place par Amaury de la Moussaye (Guitton, 2007, p. 20). Peut-être faut-il attribuer à ce dernier la construction des tours du Gouverneur et Beaumanoir, où ne figurent pas les armes des Coëtquen?

Sur le plan défensif, l'évolution des organes de tir permet également de suivre la progression du chantier. À l'exception des canonnières ménagées dans l'allège des baies, tous les postes de tir sont cloisonnés, ou du moins isolés les uns des autres. Chacun d'eux est desservi par un couloir voûté, avec ou sans niche de retrait pour le servant, débouchant sur une casemate dont le plan triangulaire tend à se systématiser d'une tour à l'autre. De la même façon, l'amélioration des canonnières marque une réelle progression. Au sud, les tours Penthièvre et de Coëtquen sont équipées d'orifices à fente courte pour l'usage privilégié du canon. Seule la tour Penthièvre se signale par l'utilisation occasionnelle d'archères-canonnières en croix, sans que cela ne traduise pour autant d'écart chronologique entre les deux tours. À l'inverse, les embrasures à évasement externe et à orifice rectangulaire présentes au troisième niveau de la tour $\mathrm{du}$ Connétable marquent une réelle évolution par rapport aux modèles antérieurs et constituent une réponse aux progrès de l'artillerie des années 1470 (Crouy-Chanel,

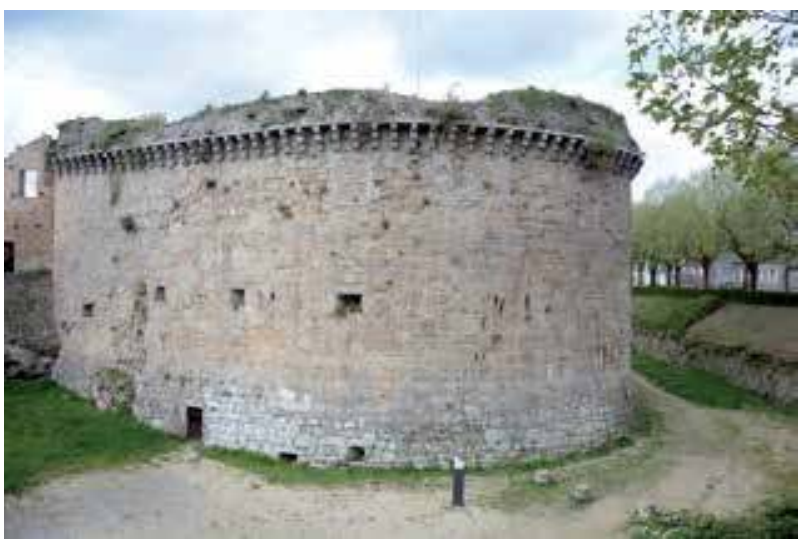

Figure 10 : Vue générale de la tour Beaumanoir, à Dinan.

Figure 10: View of the Beaumanoir Tower in Dinan.

Cliché / Picture : M. Dufeil

2020, p. 334-346) ${ }^{17}$. La présence exclusive de telles embrasures aux tours du Gouverneur et Beaumanoir laisse ainsi présumer de leur caractère postérieur. Cette forme de canonnière est caractéristique de la fortification bretonne sous François II : on la retrouve à la porte Sauvetout et à la tour du Fer à Cheval de Nantes, aux tours Raoul et Surienne à Fougères, ou encore à la tour Major à Concarneau, toutes érigées dans les années 1480 (Martineau, 2011, p. 202-203; Faucherre, 2016, p. 290; Faucherre, 2007, p. 75-76). À la tour Beaumanoir, les ouvertures de tir sont légèrement surélevées par rapport au sol intérieur de la casemate $(0,15$ à $0,30 \mathrm{~m})$. Elles sont dotées d'un trou de visée rectangulaire de plus ou moins $0,20 \mathrm{~m}$ de côté, surmonté par un cran de mire de 0,17 $\mathrm{m}$ de haut et de 0,04 $\mathrm{m}$ de large en moyenne. Des ancrages de calage ont été prévus dans la plupart des casemates. Ménagés au ras du sol, dans les joues de l'ébrasement, ils prouvent l'utilisation de canons à boîte fixés sur affût (Martineau, 2016b). Enfin, tirant parti de l'évasement externe de l'embrasure, le tube est servi en avant, sa bouche débordant vers l'extérieur. De cette façon, la partie antérieure de la volée repose sur la lèvre inférieure de l'orifice de tir. La distance entre la fenêtre de tir externe et les encoches de calage, variable d'une casemate à l'autre - de 2,80 à 3,80 m - permet ainsi d'envisager le recours à des armes de calibre moyen, d'une longueur minimale de $2 \mathrm{~m}$. Certaines d'entre elles figurent peut-être dans l'inventaire de l'artillerie bretonne établi en 1495 sur ordre du roi. À Dinan, le commissionnaire recense une cinquantaine de pièces, réparties dans une quinzaine d'ouvrages. La plupart

17. Il est possible que les ouvertures à évasement externe présentes au troisième niveau de cette tour aient été ménagées postérieurement, car contrairement aux orifices en louche prévus à tous les niveaux, leur encadrement n'est pas matérialisé en pierre de taille. 
appartiennent alors à la catégorie des couleuvrines et des ribaudequins à chargement par boîte, de quelques centaines de livres ${ }^{18}$.

En somme, la confrontation des sources documentaires et matérielles paraît confirmer l'idée d'une seconde phase de travaux, débutant en 1476 par l'élargissement des douves et l'érection d'un puissant talus de contrescarpe, et se poursuivant par la construction de cinq grandes tours à canon, évoluant d'un ouvrage à l'autre de façon empirique, jusqu'à l'aboutissement d'une formule standardisée dans les années 1480 . Bien sûr, les travaux réalisés à Dinan ne sont pas isolés : à partir de 1477, une dernière grande phase de fortification est également signalée à Nantes, cœur du pouvoir ducal (Dreillard, 2017, p. 343). Cette campagne s'achève par l'édification de la tour du Fer à Cheval, dans l'angle nord-est du château des ducs (Martineau, 2016a). Démarrée en 1486-1487 et achevée au plus tard en 1491, cette tour serait l'une des dernières réalisations ducales avant la mise au pas royale (Ibid., p. 277; Faucherre, 2016). Or, elle n'est pas sans rappeler la tour Beaumanoir de Dinan : dimensions horsnormes (30 m de long et $22 \mathrm{~m}$ de large à Nantes, contre $27 \mathrm{~m}$ et $22 \mathrm{~m}$ à Dinan), épaisseurs de mur considérables (7 à $8 \mathrm{~m}$ dans les deux cas, voire plus), casemates triangulaires à couloir latéral de 6 à $8 \mathrm{~m}^{2}$ débouchant sur des embrasures de tir à évasement externe ouvertes sur deux crêtes de feu pour un tir de balayage au moyen de canons fixés sur affût... Reste que la tour dinannaise se démarque par l'absence de couvrement et d'un quelconque élément de résidence. Or, de la même façon que la tour du Fer à Cheval semble avoir été bâtie avec empressement, peu de temps avant la débâcle de 1488, il est possible que la construction de la tour Beaumanoir ait été également précipitée, au point de ne privilégier que le seul aspect défensif. Nous verrons plus loin que certains indices accréditent cette hypothèse.

\section{Les défenses avancées : boulevards et fausse-braie}

Outre la construction de nouvelles tours à canon, le renforcement de l'enceinte dans la seconde moitié du $\mathrm{Xv}^{\mathrm{e}} \mathrm{s}$. implique la mise en œuvre d'un certain nombre de défenses avancées. À l'exception de la porte du Jerzual, chacune des entrées de ville est dotée d'un ouvrage extérieur, bâti en avant du passage. Ces boulevards forment un premier filtre défensif, destiné à renforcer la défense de la porte. Nous ne savons pas précisément de quand datent les boulevards dinannais, mais il est

18. ADLA, E216-13. En 1489, Charles VIII ordonne le transfert de « toute la grosse artillerie et les matières qui sont à Dinan » (Gesret, 1998, p. 34). On ne sait donc pas jusqu'à quel point l'inventaire de 1495 rend compte de la composition du parc d'artillerie tel qu'il existe à Dinan dans les années 1480 . certain qu'ils existent avant la fin du $\mathrm{Xv}^{\mathrm{e}}$ s. En 1484 en effet, on signale l'existence du "Bellouart de la porte du Guischet " (Maheo, 1852, p. 9). Plus exposé, le quart nord-ouest de l'enceinte est placé sous la protection supplémentaire d'une fausse-braie défilant le bas des courtines. Démolie au XviII ${ }^{\mathrm{e}}$ s., comme la plupart des ouvrages avancés, cette fausse-braie est encore partiellement conservée sur le front nord, à proximité des tours de Lesquen et Beaumanoir (fig. 11). D'après J. Mesqui et $S$. Gesret, sa construction serait postérieure à celle des grandes tours à canon de la fin du $\mathrm{Xv}^{\mathrm{e}} \mathrm{s}$., tous deux attribuant la paternité de cette défense aux travaux entrepris par le duc de Mercœur, à la fin du Xvi ${ }^{\mathrm{e}}$ s. (Mesqui, 1997, p. 151; Gesret, 1998, p. 334). Plusieurs indices suggèrent au contraire une date antérieure. Par leur forme et leurs dimensions, les grandes archères-canonnières ajourant le mur de fausse-braie sont assez caractéristiques des productions du milieu du $\mathrm{Xv}^{\mathrm{e}} \mathrm{s}$. : l'orifice circulaire, de $0,20 \mathrm{~m}$ de diamètre, est joint à une fente verticale d' $1 \mathrm{~m}$, grossièrement évasée aux deux tiers pour favoriser le tir à l'arme de jet. Masquées par le talus de contrescarpe, ces embrasures devaient permettre de battre le fond du fossé par un tir rasant ciblé à hauteur de jambes au moyen d'un canon posé sur affût ${ }^{19}$. Enfin, nous verrons plus loin qu'à la fin du Xvi ${ }^{\mathrm{e}}$ s., le duc de Mercœur accorde un soin attentif aux angles morts et aux ouvertures de tir multiples et dérobées, favorisant les feux croisés et le détachement d'ouvrages pentagonaux. Aussi la faussebraie et sa forme archaïsante de tir direct s'accordentelles assez mal avec le programme architectural adopté de façon générale par le chef ligueur.

\section{Un espace de circulation périphérique?}

Plusieurs indices tendent à démontrer l'existence d'une lice défilant le revers des courtines sur au moins une partie du périmètre fortifié. Dans un mandement daté de 1477, le duc François II ordonne la démolition de l'ensemble des constructions situées à moins de 8 pieds du mur d'enceinte, soit environ $2,60 \mathrm{~m}^{20}$. Deux siècles plus tard, le témoignage de Dubuisson-Aubenay fait écho à cette

19. Bien sûr, compte tenu de l'épaisseur des terres accumulées d'un côté, et du faible calibre des armes employées de l'autre, on imagine bien que le tir de plein fouet achevant sa course dans le flanc du talus ne saurait suffire à l'endommager. 20. ADLA, registres de la Chancellerie de Bretagne, B08, fo $190 \mathrm{~V}^{\circ}$. Il est possible également que l'ordre de démolition s'applique à des bâtiments accolés à l'extérieur du mur d'enceinte, en préalable à la construction de la fausse-braie. Notons que la distance indiquée par le duc (2,60 m) correspond à peu près à la largeur de la lice conservée au revers du mur de fausse-braie $(2,80 \mathrm{~m})$. De plus, c'est également en 1477 que le rythme des travaux s'accélère, et qu'on commence à faire appel à une main-d’œuvre spécialisée. Enfin, en 1484, « ung jardrin [...] sus près la porte SaintMalo hors ceste ville » est pris « pour lenlaissement et agrandissement des douves et foussés $॥$, ce qui prouve que les abords extérieurs de l'enceinte sont occupés (Maheo, 1852, p. 9). 
mesure, le voyageur décrivant une muraille qui se trouve "partout éloignée des bastimens, dont elle est séparée par jardinages et terrain, pour la retrancher " (DubuissonAubenay, 1636, p. 113). Enfin, plusieurs extraits de plan datés des années 1784-1786 évoquent l'existence d'un " chemin de ronde " défilant le revers des courtines en de nombreux points de l'enceinte (fig. 12). De nos jours, le tracé de cette desserte reste lisible par endroits : à l'ouest de la tour Beaumanoir peut-être, et de façon plus vivace à l'ouest de la porte du Jerzual. À cet endroit, le passage large de $4 \mathrm{~m}$ - longe le mur d'enceinte jusqu'à bifurquer en direction de la porte Saint-Malo. Ce corridor périphérique paraît donc destiné à assurer une desserte rapide entre chaque ouvrage. Dans cet espace clos, quelques rampes ménagées ici et là permettent de rejoindre le haut des courtines. Enserrée entre le mur d'enceinte et un haut mur de clôture, cette lice est en grande partie déconnectée du reste de la ville. En fait, elle n'apparaît que brièvement dans l'espace urbain, de part et d'autre de chaque rue se développant au droit de la muraille, incluant bien évidemment les axes de pénétration principaux, mais également les quelques voies secondaires percées ici et là, entre les îlots d'habitations. À titre de comparaison, les recherches opérées sur le tracé de l'enceinte médiévale d'Angers ont révélé l'existence d'une desserte semblable, contemporaine de la construction de la muraille, dans les années 1230 (Hunot, 2015).

\section{LES FORTIFICATIONS À L'ÉPOQUE MODERNE (XVI ${ }^{-}$-XVIII' ${ }^{\mathrm{e}}$ S.)}

\section{L'entretien des fortifications au $\mathrm{XVI}^{\mathrm{e}} \mathrm{S}$.}

Malgré les efforts entrepris, les défenses mises en œuvre à Dinan restent inutiles. Suite à la défaite bretonne de Saint-Aubin-du-Cormier à la fin du mois de juillet 1488,

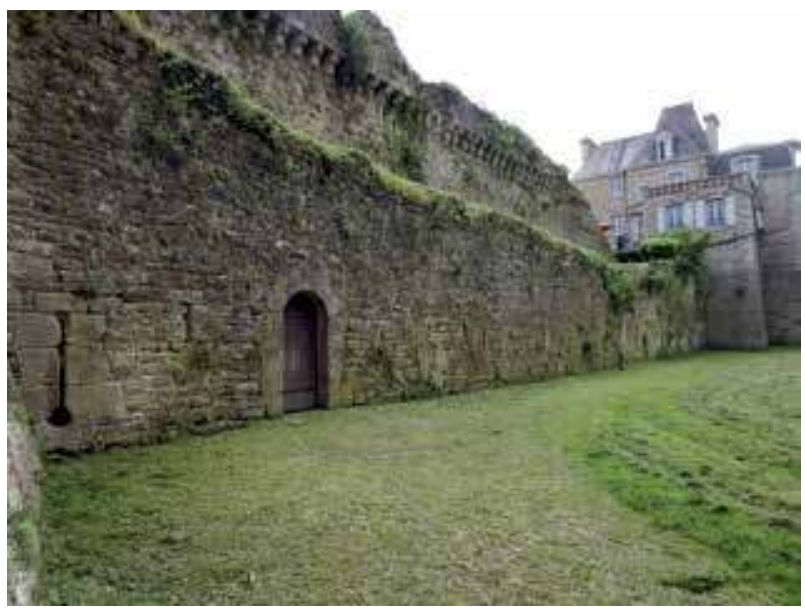

Figure 11 : Vue d'une portion de fausse-braie conservée à l'ouest de la tour Beaumanoir, à Dinan.

Figure 11: View of a portion of the covered way preserved to the west of Beaumanoir Tower, in Dinan.

Cliché / Picture : M. Dufeil

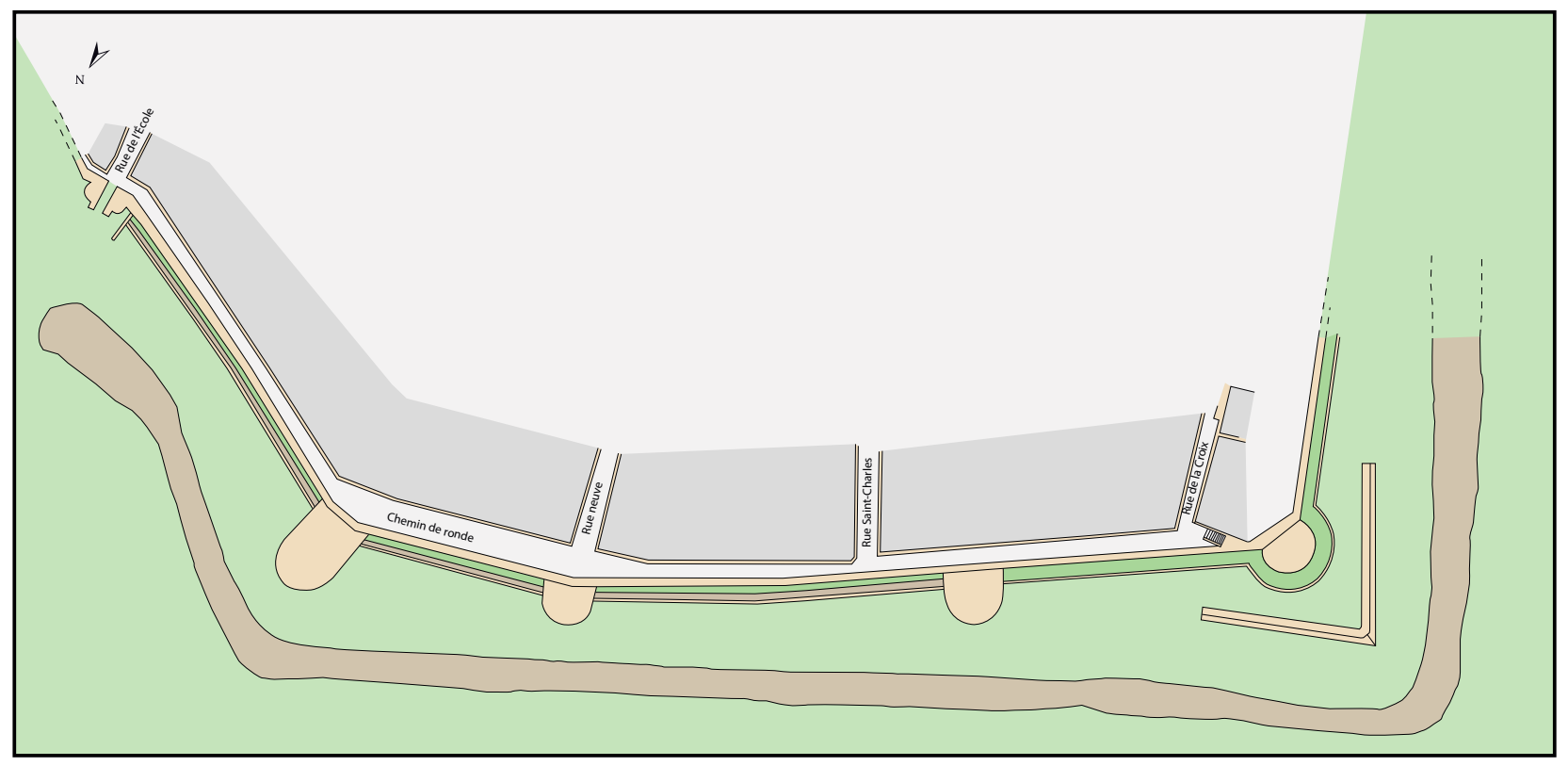

Figure 12 : Extraits de plans datés de 1784-1786 figurant l'existence d'une desserte accolée au mur d'enceinte.

Figure 12: Extracts from plans dated 1784-1786 showing the existence of a service path at the back of the wall.

Dessin / Drawing : M. Dufeil, d’après une série de plans conservés aux Archives nationales et reproduits dans Gesret, 1993 / M. Dufeil, based on a series of plans kept in the National Archives and reproduced in Gesret, 1993 
les troupes françaises débarquent à Dinan. Sans espoir de résistance et souhaitant éviter une mise à sac, la ville capitule (Guitton, 2007, p. 7). Comme le reste du duché, Dinan entre dans le domaine royal et perd son rôle de place forte ducale. À cette occasion, et jusqu'en 1516, elle passe sous le contrôle du vicomte Jean II de Rohan, allié du roi Charles VIII. En parallèle, les défenses urbaines continuent à être entretenues. En 1498, le comte Guy de Rochefort, chancelier de France, ordonne que «la place et chasteau de Dynan » soient entretenus « afin que nul inconvenient nen adviengne » (Gesret, 1998, p. 36). En 1503 encore, la ville reçoit le droit de lever un « vingtain sou " pour une durée de six ans, et l'on signale des travaux de réfection touchant aux portes de ville en 1514 (Ibid.). Enfin, en 1520 et 1522, on trouve mention d'un certain Guillaume Le Bascle, receveur ordinaire à Dinan, chargé de la gestion des fonds nécessaires à la réparation des fortifications (Guitton, 2007, p. 30). Cela étant, ce n'est qu’à la fin du siècle, dans le cadre de la guerre de la Ligue, que les défenses dinannaises retrouvent un réel intérêt militaire. Entre-temps, il semblerait qu'on ait cessé d'entretenir les anciennes douves, qui servent de dépotoir pour les habitats et ateliers proches. En effet, les sondages archéologiques réalisés au pied du mur d'enceinte et à proximité de la porte de l'Hôtellerie ont révélé la présence de niveaux vaseux conservés sous $2 \mathrm{~m}$ de remblais modernes. Épais d'environ 2,50 m, ces niveaux ont livré un important mobilier attribuable à la fin du Xvi ${ }^{\mathrm{e}} \mathrm{s}$. (Ménez, 1991 ; 1993).

\section{Le chant du cygne : l'évolution des fortifications au temps de la Ligue (fin du $\mathrm{XVI}^{\mathrm{e}} \mathrm{s}$.)}

Achevant la période troublée des guerres de Religion, la guerre de la Ligue débute en 1589 et s'achève en 1598. En Bretagne, où le protestantisme est assez peu représenté, le conflit prend une tournure plus politique que religieuse, entre les partisans de l'ordre établi et les défenseurs de l'unité religieuse. La situation est d'autant plus conflictuelle que le gouverneur de Bretagne - le duc de Mercœur - est également le chef des ligueurs bretons. En 1585, il se voit remettre par traité les places fortes de Concarneau et de Dinan. Après l'assassinat du chef de la Ligue en 1588, il devient de plus en plus méfiant à l'égard du pouvoir royal et décide de renforcer les fortifications dinannaises.

Menés dans l'urgence, les travaux entrepris sont caractéristiques d'une époque marquée par l'émergence et le développement du système bastionné, qui constitue la véritable réponse au canon faisant brèche (Crouy-Chanel, 2007, p. 19). Au sud-ouest, la tour-résidence édifiée par Jean IV dans les années 1380 devient partie intégrante d'un réduit défensif, tourné tant vers l'extérieur que vers l'intérieur de la ville. L'ancienne porte du Guichet est condamnée et une galerie d'escarpe abritée et ventilée est plaquée au revers de la courtine médiévale, entre la tour de Coëtquen et la tour ducale. Armée pour le tir épaulé au ras du sol, cette gaine projette un feu croisé en direction de la ville. Enfin, une terrasse d'artillerie est aménagée à hauteur du second niveau de la tour ducale et un large fossé est creusé de façon à isoler la citadelle du reste de la ville (fig. 13). En parallèle, le duc de Mercour fait renforcer le front nord de l'enceinte, plus largement exposé au danger. Condamnant le passage du Jerzual à l'est, il prévoit la construction d'une série d'ouvrages détachés et remparés. Faute de temps, cette œuvre reste inachevée. Seul en témoigne aujourd'hui un ouvrage en éperon, autrefois solidaire d'un talus remparé construit en avant de la porte du Jerzual. À titre de comparaison, les travaux amorcés à Dinan font écho à ceux que le chef ligueur pilote au même moment à Nantes, au faubourg du Marchix, où il poursuit la construction d'une enceinte bastionnée qui reste également inachevée (Dreillard, 2017, p. 344-345). Les plateformes d'artillerie accolées contre les courtines de la ville close médiévale rappellent, quant à elles, les levées de terre plaquées contre les courtines du château de Léhon, qui garde l'accès à Dinan depuis le sud (Ibid., p. 346; Hayot, 2017, p. 89). Finalement, comme pour les fortifications érigées un siècle plus tôt, les défenses mises en œuvre par le duc de Mercœur restent inutiles : en 1598, une conjuration livre la ville aux troupes royales. Repliée dans leur citadelle, la centaine d'hommes demeurée en garnison capitule rapidement (Guinebaud, 2011, p. 103-104).

\section{Le déclin progressif : de l'entretien à l'abandon (XVII' s.)}

Au XVII ${ }^{e}$ s., la ville de Dinan se transforme. Gagnée par l'esprit de la Contre-Réforme, elle accueille quatre nouveaux couvents et devient une terre d'élection pour la reconquête catholique. Cette progression religieuse ne marque pas seulement les esprits, mais également le paysage : en 1631, les six couvents que compte la ville close de Dinan se partagent plus d'un tiers de la surface urbaine (Stephant, 1947, p. 72). Or, aucune de ces nouvelles fondations ne semble rencontrer de problèmes dus à la présence de bâtiments laïques, ce qui tend à prouver que l'espace enclos est encore peu urbanisé. Un voyageur anonyme de passage à Dinan en 1635 confirme cette idée : selon lui, «ladicte ville [...] n'est pas peuplée, et les convens et jardins des particuliers en occupent une moytié " (La Borderie, 1890, p. 141). Aussi l'enceinte urbaine ne paraitt-elle pas constituer un frein à l'agrandissement de la ville. Au contraire, elle continue de faire l'objet de travaux d'entretien comme l'atteste, en 1613, l'autorisation donnée aux officiers locaux de percevoir des 


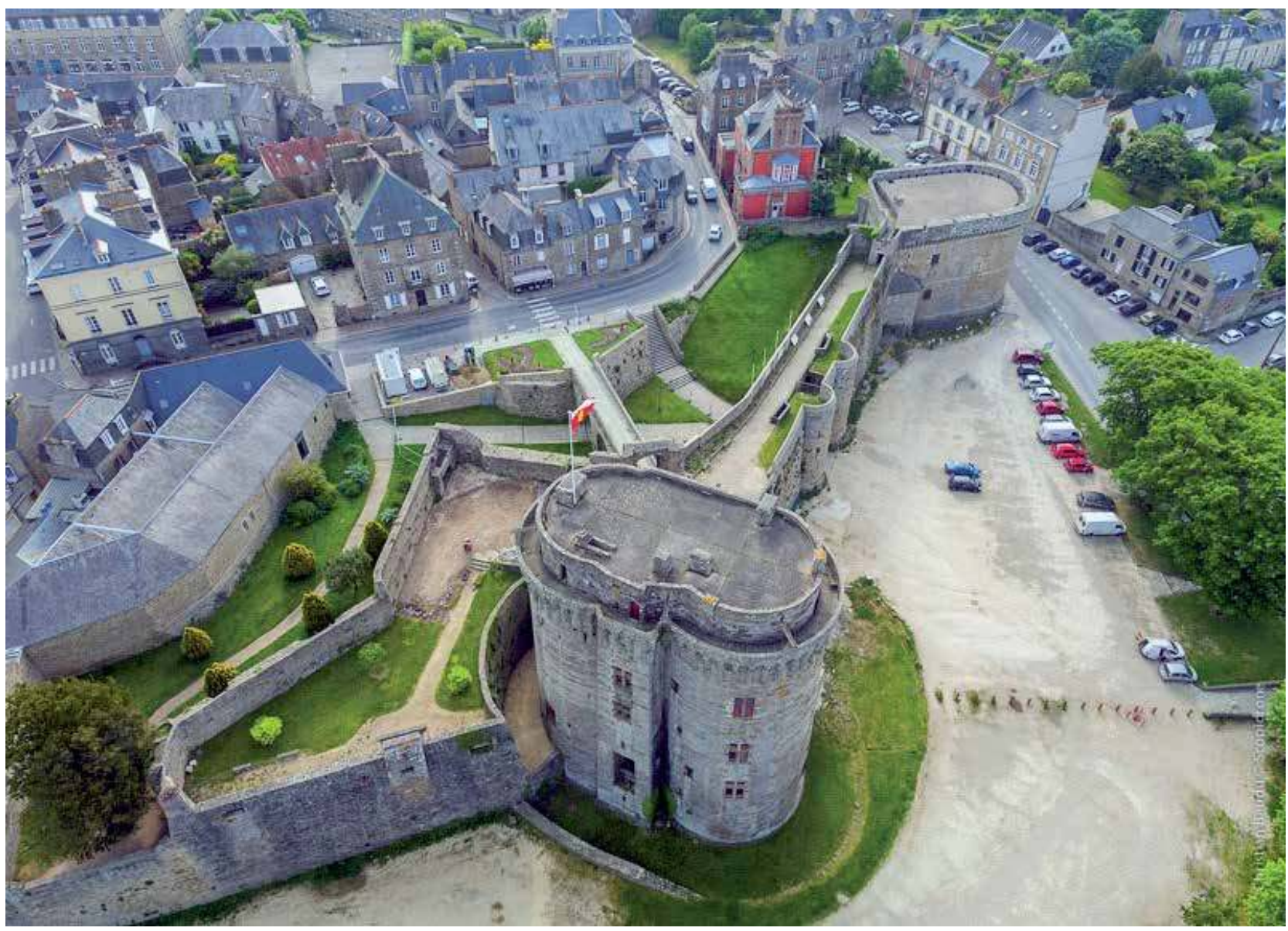

Figure 13 : Vue générale de la citadelle bâtie à la fin du $\mathrm{XVI}^{\mathrm{e}} \mathrm{s}$. par le duc de Mercœur. Ce réduit comprend au premier plan la grande tour ducale, la porte du Guichet et la tour de Coëtquen. L'ensemble est relié par une plateforme d'artillerie tournée vers l'intérieur de la ville, et isolée de celle-ci par un fossé en partie conservé.

Figure 13: View of the citadel built at the end of the 16th century by the Duke of Mercoeur. This citadel includes the ducal tower, the Guichet gate and the Coëtquen tower. The whole is connected by an artillery platform facing the city and isolate from it by a moat.

Cliché / Picture : C. Baudu, Scopidrone

taxes sur les boissons et des droits d'octroi sur diverses marchandises, afin de leur permettre de "relever a neuf la muraille [...] en plusieurs endroictz " (Gesret, 1998, p. 38). Sur demande des bourgeois de Dinan, le roi autorise la construction d'une nouvelle porte au sud de la ville, en remplacement de celle du Guichet. Quant au passage $\mathrm{du}$ Jerzual, les marchands doivent encore patienter vingt ans avant de pouvoir entamer le talus remparé qui barre l'accès au port (Aubry, 1897, p. 6). Entre-temps, lors de son passage à Dinan, Dubuisson-Aubenay note qu'une partie du mur d'enceinte a été refaite récemment, suite à un effondrement (Dubuisson-Aubenay, 1636, p. 114). Cela étant, l'auteur constate également que la muraille est " terrassée en quelques endroits " et que l'une des tours est " plantée en jardinet fort joli " (Ibid., p. 113). Ce dernier point annonce la suite : en 1683, l'inventaire pour la réformation du Domaine du roi dresse l'image d'une place forte quasi abandonnée, accaparée par les civils et réduite à la garde des prisonniers de guerre ${ }^{21}$. Pourtant, bien que délabrées, les défenses tiennent encore le coup et pourraient se rendre utiles sur le plan militaire, sous réserve de quelques travaux de rénovation. C'est là tout l'enjeu de la venue de l'ingénieur militaire Siméon Garengeau.

\section{L'intervention de Siméon Garengeau à la fin du XVII ${ }^{\mathrm{e}}$.}

En 1693, l'ingénieur du roi, Siméon Garengeau, est dépêché à Dinan afin d'y établir un devis estimatif des sommes à engager pour la remise en état des défenses de la ville ${ }^{22}$. Le détail de son constat est assorti d'un plan général de la ville et de ses environs, présentant avec force détails l'état des fortifications à la fin du XVII e s. (fig. 3).

21. ADLA, registres de la Chancellerie de Bretagne, B 1320, procès-verbal de la situation des fossés et corps de garde de Dinan à la fin du XVII $\mathrm{S}$. 22. ADIV, C 492. 
Selon son témoignage, " cette place, bien loin d'avoir esté entretenue, depuis un tems, a non seulement esté négligée, mais ruynée et dégradée par un chacun ». Après avoir exposé l'étendue des réparations nécessaires pour chaque ouvrage, l'ingénieur soumet deux devis : l'un pour la remise en état complète des défenses, l'autre pour le simple dégagement des terres amoncelées et la reprise des parties sommitales en vue d'y armer des canons. Jugé trop onéreux par la couronne, le premier projet n'est pas mis en œuvre : à l'heure où l'intérêt stratégique de la Bretagne tient en premier lieu à ses défenses côtières, sans doute estime-t-on inutile d'investir tant d'argent dans la remise à neuf de fortifications campées plus avant dans les terres. Or, l'étude architecturale démontre que le roi ne se contente pas pour autant du second projet. Ainsi, à la tour du Gouverneur, l'ingénieur tire parti de l'énormité de la masse couvrante pour y aménager un troisième niveau. Cela dit, malgré l'intervention de Garengeau, les fortifications de Dinan ne retrouveront jamais leur importance militaire. Cédées, afféagées puis peu à peu démolies au XVIII ${ }^{e}$ s. (Hamon, 1976), elles serviront également de prison, avant d'être finalement classées au titre des Monuments historiques à la fin du XIX ${ }^{e} s$.

\section{LES RÉCENTS APPORTS DE L'ARCHÉOLOGIE À L'ÉTUDE DU FRONT NORD : LA PORTE SAINT-MALO ET SES ABORDS}

\section{La porte Saint-Malo: une production antérieure au XIII ${ }^{\mathrm{e}} \mathrm{s}$ ?}

En parallèle à l'état des connaissances développé jusqu'ici, une opération de prospection archéologique a été menée sur une partie du front nord, correspondant à la porte Saint-Malo et ses abords immédiats. Les données collectées lors de cet examen ont permis d'établir une chronologie d'évolution plus fouillée que ce que suggère l'observation succincte des principaux traits architecturaux de l'ouvrage. Les résultats obtenus restent néanmoins partiels, jusqu'à la réalisation d'une étude plus approfondie.

En l'état, il est difficile de se prononcer avec certitude sur la physionomie initiale de cette entrée de ville. En effet, l'analyse du passage d'entrée montre que celui-ci pourrait avoir été modifié pour permettre l'incorporation de nouveaux éléments d'arrêt, dont une herse, un assommoir et deux couples d'archères (pl. 4). Le tout est surmonté vers l'extérieur par une niche décorative décaissée dans l'épaisseur de l'arcade de tête. Au sud, cet ensemble paraît avoir été soudé avec plus ou moins de soin à une maçonnerie antérieure. Il est possible, par conséquent, que l'entrée d'origine ait été constituée par une porte non flanquante, simplement ménagée dans l'épaisseur de la courtine, à l'image de celle bâtie dans la première moitié du XII ${ }^{\mathrm{e}}$ s. pour la chemise du château de Gisors (Mesqui, 1991, p. 308). Côté ville d'ailleurs, la porte Saint-Malo s'inscrit dans une large arcade en plein cintre, semblable à celle mise en œuvre à Gisors. Le mur de gorge de la porte Saint-Malo conserverait-il quelques éléments de maçonnerie antérieurs à l'enceinte du XIII ${ }^{\mathrm{e}}$ s. ? Pourrait-il s'agir, dans ce cas, d'une survivance des défenses signalées par Al-Idrīsī vers le milieu du XII ${ }^{\mathrm{e}}$ s.? La proximité de cette première clôture, dont le tracé présumé s'étend à seulement $30 \mathrm{~m}$ au sud de la porte Saint-Malo, renforce nos soupçons, mais l'hypothèse est encore trop fragile à ce stade.

\section{La construction du châtelet dans le courant du XIII ${ }^{\mathrm{e}} \mathbf{S}$.}

La mise en défense du passage d'entrée est probablement contemporaine de la construction du châtelet. Les deux tours qui le composent adoptent un plan semi-circulaire à gorge droite et sont bâties sur deux niveaux d'archères (pl. 1). Construites à $3 \mathrm{~m}$ l'une de l'autre, les tours sont reliées par un corps central commandant le passage d'entrée vers la ville. Sur le plan topographique, la porte est établie en limite de plateau, sur un point de rupture de pente dévalant vers l'est, jusqu'à la dépression du Jerzual (pl. 2). Pour assurer la stabilité structurelle de l'édifice, la tour bâtie du côté de la pente est donc pourvue à la base d'un talus plus incliné. La tour ouest repose quant à elle sur une base creuse, dans laquelle se trouve ménagé un niveau aveugle ( $\mathrm{N}-1)$. En l'absence d'ouvertures défensives et d'un accès direct et indépendant, les possibilités fonctionnelles du N-1 sont réduites : il s'agit soit d'un cachot, soit plus vraisemblablement d'un espace utilitaire. Une puissante voûte maçonnée, faite de larges dalles disposées en porte-à-faux, surmonte ce niveau. Au centre de la voûte, un trou d'homme relie le $\mathrm{N}-1$ au rez-de-chaussée (N0). À ce niveau-ci, les deux tours présentent des dispositions semblables : une salle bâtie selon un plan semi-circulaire étiré en " $U$ » et percée au front et sur les flancs par des ouvertures défensives. La tour ouest dispose en outre d'une latrine à fosse, installée à l'extrémité d'un couloir mural ménagé dans l'épaisseur de la courtine, ainsi que d'une petite cheminée destinée à améliorer le confort des gardes. Enfin, chacune des salles du N0 est dotée d'une voûte semblable à celle du N-1.

L'accès au N0 est assuré par un couple de portes établi à la gorge de l'ouvrage (pl. 5). Chacune d'elles semble avoir été percée en sous-@uvre, consécutivement à la construction du châtelet. Un écart d'environ $1 \mathrm{~m}$ sépare les deux seuils, la porte d'accès à la tour ouest étant située plus haut que celle menant à la tour est. D'après $S$. Gesret, le sol du N0 aurait été rehaussé dans la tour ouest, d'où 
l'écart entre les tours (Gesret, 1998, p. 90). En effet, l'auteur observe que l'archère qui garde le passage d'entrée est recoupée à mi-hauteur par le sol de la salle, indiquant par là même une évolution du niveau de circulation (fig. 14). Pourtant, l'aire de pierre établie en avant du conduit de cheminée est de niveau avec le sol, et l'accès vers la latrine est encore précédé par un seuil surélevé formant marche, ce qui suggère au contraire que le niveau n'a pas évolué. Il est donc possible que l'écart de niveau entre les deux tours soit plus simplement dû à l'effet du point de rupture de pente, qui oblige à asseoir la tour est en contrebas de la tour ouest et crée ainsi un effet d'asymétrie entre les deux (pl. 2). En ce sens, la fente d'archère recoupée à l'ouest pourrait correspondre à un repentir, à moins que les constructeurs n'aient été tout simplement contraints de s'aligner sur la fente opposée, et ce faisant de sacrifier la partie basse de l'ouverture?

Sur le plan défensif, le premier niveau de la porte SaintMalo est doté d'une série d'archères à niche débouchant invariablement sur une fente simple (pl. 3). Couvertes par un simple linteau, ces niches sont plus ou moins larges, selon que leur embrasure dépasse ou non la largeur de l'ébrasement délimitant la fenêtre de tir. Aussi différenciet-on les niches " débordantes ", " semi-débordantes" ou "simples », c'est-à-dire équivalentes à la largeur de l'ébrasement. Ici, la préférence occasionnelle pour une niche plus étroite semble avant tout dictée par la place disponible et la volonté de ne pas trop fragiliser la construction par des débordements systématiques. Notons par ailleurs que des archères à niche « simple » sont également mises en œuvre au troisième niveau de la tour maitresse de Najac (Aveyron), datée des années 1250-1260, et peutêtre aussi au premier niveau de la grande tour nord-ouest du château de Montafilan, près de Corseul, attribuée par Christophe Amiot à la seconde moitié du XIII ${ }^{\mathrm{e}}$ s. (Hayot, 2015, Monographies, vol. 3, p. 1122 et 1129; Amiot, 1999, p. 372-373). Dans l'ensemble d'ailleurs, le châtelet de la porte Saint-Malo reprend une grande part des standards de la fortification capétienne telle qu'elle se développe dans le courant du XIII ${ }^{e}$ s., que ce soit par le diamètre ou la hauteur de ses tours, l'épaisseur de ses maçonneries, la structure de son passage d'entrée ou la configuration de son schéma défensif. De façon plus spécifique, l'exclusivité de l'archère à niche, la présence de quelques commodités élémentaires et l'amorce d'un soin décoratif dans la mise en œuvre du passage d'entrée annoncent le dernier tiers du $\mathrm{XIII}^{\mathrm{e}} \mathrm{s}$. Il semble donc possible d'attribuer la construction du châtelet de la porte Saint-Malo au gouvernement du duc Jean I ${ }^{\text {er }}$, entre 1265 et 1286.

Enfin, les courtines voisines sont peut-être contemporaines de la construction du châtelet. À l'ouest notamment, la maçonnerie du mur d'enceinte paraît chaînée

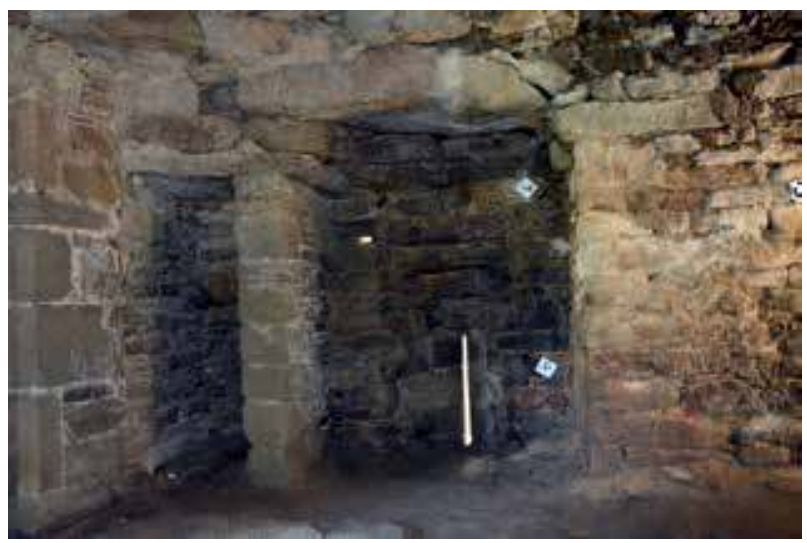

Figure 14 : Dinan, porte Saint-Malo, premier niveau de la tour ouest.

Figure 14: Dinan, Saint-Malo Gate, first level of the West tower.

Cliché / Picture : M. Dufeil

au flanc de la tour. D'ailleurs, sur le plan structurel, l'ensemble porte-courtines forme un bloc uni et cohérent : alors que le mur d'enceinte adopte un tracé biais dirigé vers le cœur de la dépression du Jerzual, la porte SaintMalo est établie dans un alignement divergent par rapport à la muraille. Cette situation contraire occasionne une déviation logique du tracé d'enceinte, les courtines enserrant la porte étant bâties sur deux plans différents afin d'assurer une saillie égale aux tours (pl. 3). Cela suggère que les courtines ont été élevées au départ du châtelet et en fonction même de celui-ci.

\section{L'achèvement des niveaux supérieurs à la charnière des XIII' et XIV ${ }^{\mathrm{e}}$. ?}

À hauteur du second niveau $(\mathrm{N}+1)$, le parement extérieur des tours présente une différence de mise en œuvre révélant un nouvel état de construction (pl. 1). Le couvrement des salles évolue vers une voûte en berceau continu et les archères sont désormais munies d'une fenêtre de tir sur allège, précédée à chaque fois par une niche en plein cintre. Des dispositions semblables sont également présentes au premier niveau de la porte du Guichet et il est donc possible que le second niveau de la porte Saint-Malo soit contemporain de la construction de cette entrée-ci. Par ailleurs, comme à la porte du Jerzual, les salles du $\mathrm{N}+1$ sont laissées ouvertes à la gorge et une baie quadrangulaire à faible plongée est disposée au milieu du corps central. De part et d'autre de cette ouverture, deux corbelets creux profilés en quart-de-rond se font face et témoignent de l'existence d'un volet en bois rabattable, abritant les défenseurs en cas d'attaque. Un dispositif semblable est également présent aux flancs de la tour SainteCatherine, probablement au commencement du XIves. Cette huchette est bordée par deux niches évidées, censées 


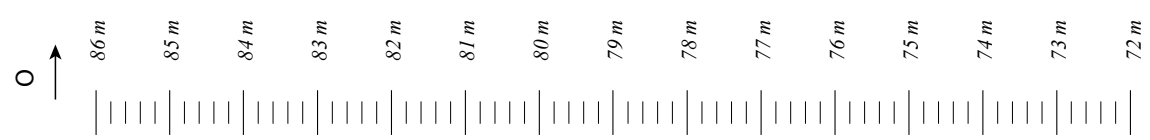

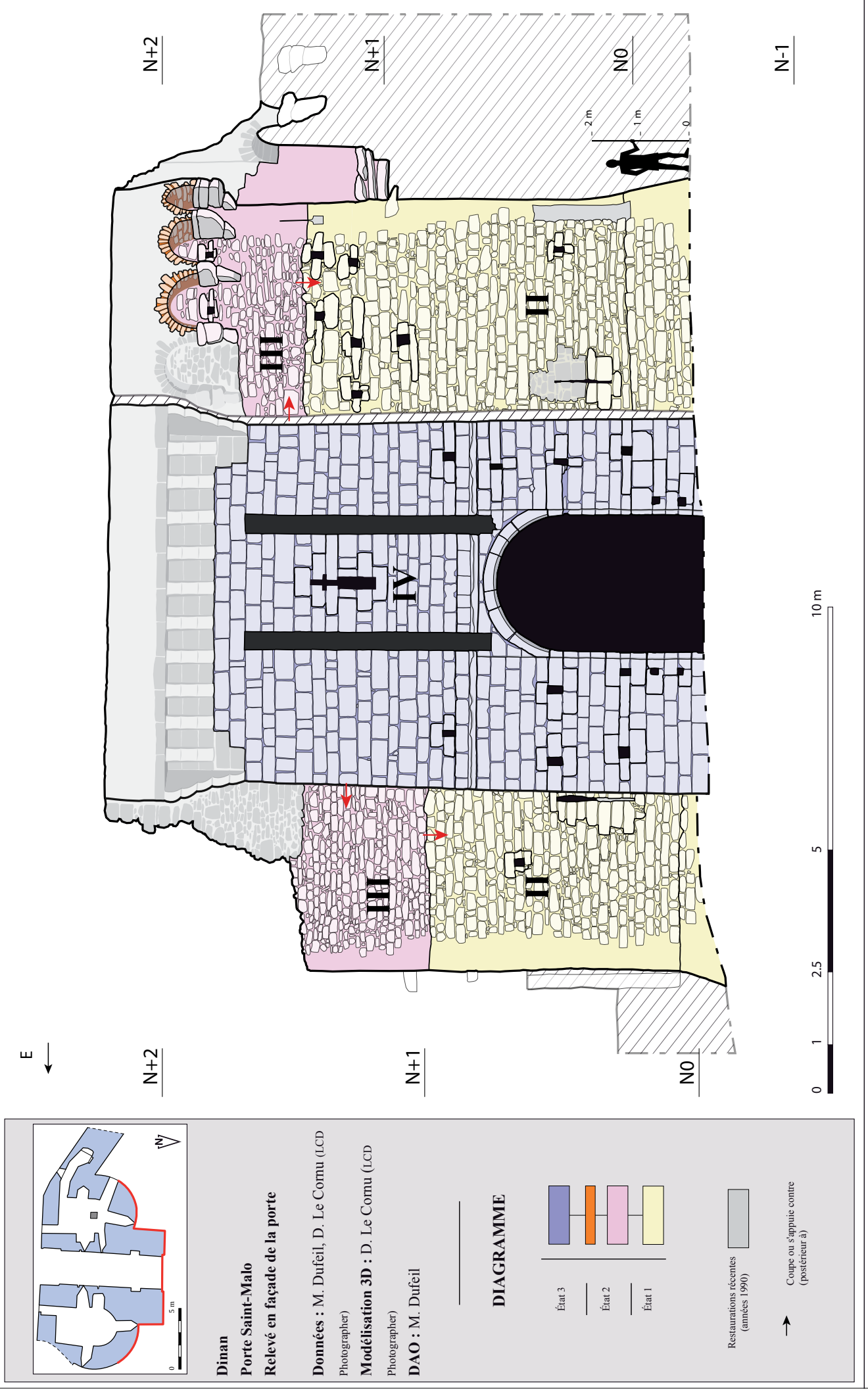

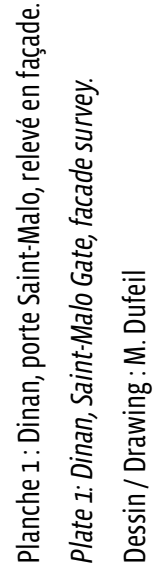




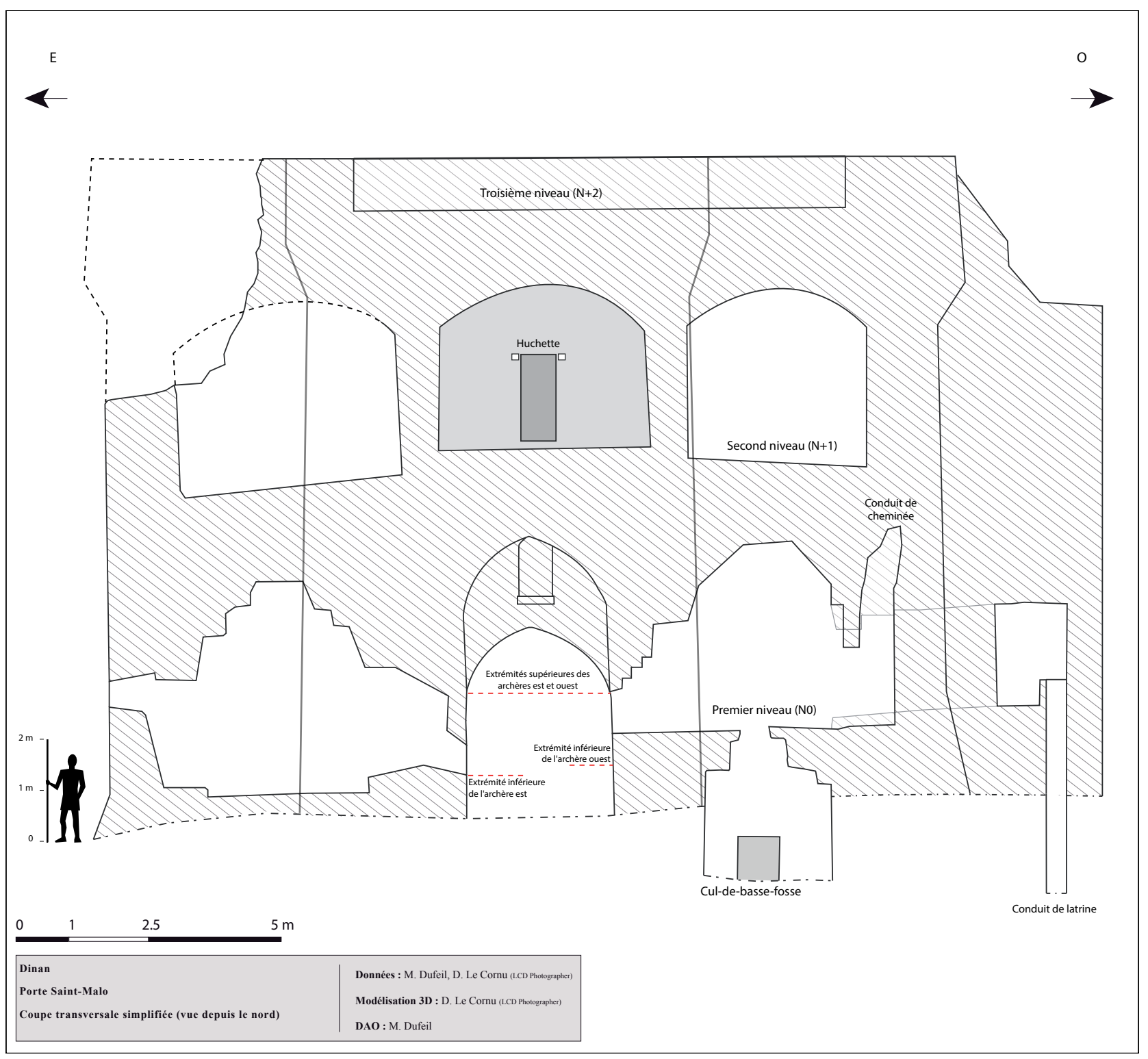

Planche 2 : Dinan, porte Saint-Malo, coupe transversale.

Plate 2: Dinan, Saint-Malo Gate, transversal section.

Dessin / Drawing : M. Dufeil

embellir l'entrée vers la ville. Enfin, au troisième niveau $(\mathrm{N}+2)$, la tour ouest est couronnée par une ceinture de mâchicoulis sur consoles, semblable à celle coiffant le sommet de la tour-porte du Jerzual. La présence de trous de boulins ménagés entre chaque évoque toutefois l'existence présumée d'un premier hourd sur corbeaux, comparable à celui que Christophe Amiot signale à la porte du Guichet (Amiot, 1999, p. 405). En l'état donc, les parties hautes de la porte Saint-Malo paraissent pouvoir être datées de la fin du XIII ${ }^{\mathrm{e}}$ s. ou du début du XIV ${ }^{\mathrm{e}} \mathrm{s}$. On insistera surtout sur la ressemblance avec la porte $\mathrm{du}$ Guichet, qui doit être légèrement postérieure au premier niveau de la porte Saint-Malo.

\section{La construction de l'avant-corps quadrangulaire et la modification des circulations au $\mathbf{X V}^{\mathbf{e}} \mathbf{S}$.}

Postérieurement à l'achèvement du châtelet, un avantcorps quadrangulaire est plaqué en avant des tours de flanquement. Cet ouvrage prolonge le passage d'entrée primitif de 4,50 $\mathrm{m}$ vers le nord, portant l'ensemble du couloir à plus de $10 \mathrm{~m}$. Pour ce faire, les maçonneries antérieures sont rognées de manière à asseoir solidement la nouvelle construction (pl. 4). Au second niveau, les flancs du nouvel ouvrage condamnent une partie des archères prévues pour le tir d'écharpe et masquent la huchette disposée au centre du corps de passage (pl. 3). Sur le plan structurel, l'en- 


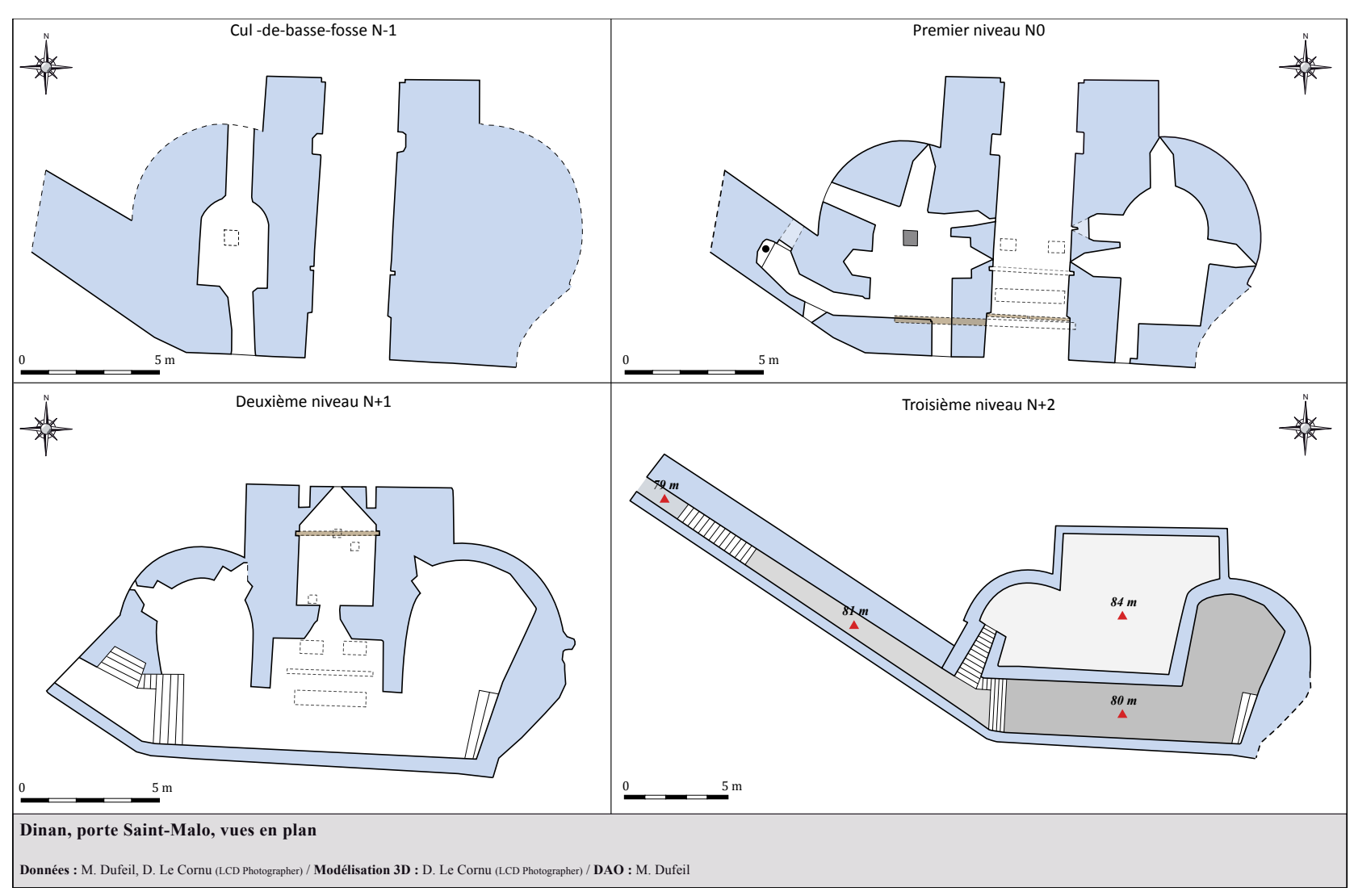

Planche 3: Dinan, porte Saint-Malo, vues en plan des niveaux N-1, N0, N+1 et N+2.

Plate 3: Dinan, Saint-Malo Gate, plans of levels $\mathrm{N}-1, \mathrm{No}, \mathrm{N}+1$ and $\mathrm{N}+2$.

Dessin / Drawing : M. Dufeil

semble est bâti de manière asymétrique. Comme pour le châtelet, ce déséquilibre résulte d'une adaptation aux conditions topographiques : afin de bien asseoir l'ouvrage, on a réparti l'essentiel de sa masse vers l'est, soit dans le sens de la pente. Sur le plan fonctionnel, l'avant-corps de la porte Saint-Malo est prévu pour accueillir un système de pontlevis à flèches, d'où la longueur de son passage. Il s'agit donc d'une adaptation à l'usage du pont mécanique, à l'instar de la porte du Jerzual. Dans ce dernier cas cependant, l'axe du balancier est incorporé au sein même de l'édifice (Corvisier, 1999, p. 43); à l'inverse, à la porte Saint-Malo, le pont-levis est " extériorisé » vers un ouvrage quadrangulaire - en fait, une tour-porte ménagée en façade - capable d'accueillir le nouveau dispositif. A priori plus rationnelle, cette solution est mise en œuvre dès les années 1360 à Provins, et jusque dans les années 1470 aux châteaux de Largoët et de Machecoul. Au second niveau enfin, l'avantcorps accueille une chambre de tir ménagée au centre de l'ouvrage, au-dessus du passage d'entrée. Cette casemate aboutit sur une fente de tir cruciforme, solidaire d'un orifice rectangulaire ouvert au ras du sol. Haut de $0,75 \mathrm{~m}$ et large de $0,25 \mathrm{~m}$, cet orifice devait permettre l'usage de différentes armes, selon qu'elles soient posées au sol sur un affût fixe, ou servies plus haut, pour un tir en plongée notamment. De façon générale, les canonnières à orifice quadrangulaire sont assez répandues en Bretagne, où elles tendent à se développer à partir des années 1450 (Mesqui, 1993, p. 314). L'archère-canonnière en bêche de la porte Saint-Malo rappelle notamment certaines des ouvertures présentes au château de Tonquédec, dans les années 1470 (Barre du Nanteuil, 1911, p. 66). En l'état, la construction de l'avant-corps semble ainsi pouvoir être datée des années 1450-1470.

Au même moment ou peu après, le châtelet bâti deux siècles plus tôt fait l'objet de nouvelles modifications. Au rez-de-chaussée, la greffe de l'avant-corps paraît entrầner une importante restructuration des espaces internes, en particulier à l'ouest (pl. 3). Dans la tour est, les niches d'archères sont réduites de chaque côté par adjonction d'un contrefort maçonné. D'après $S$. Gesret, ces réductions seraient consécutives à la mise en place de la voûte maçonnée et auraient vocation à renforcer la construction afin de lui permettre de supporter le poids colossal des dalles de couvrement (Gesret, 1998, p. 90). Or, il semble au contraire que ces réductions soient postérieures à la construction de la voûte, qu'elles chemisent par endroits 

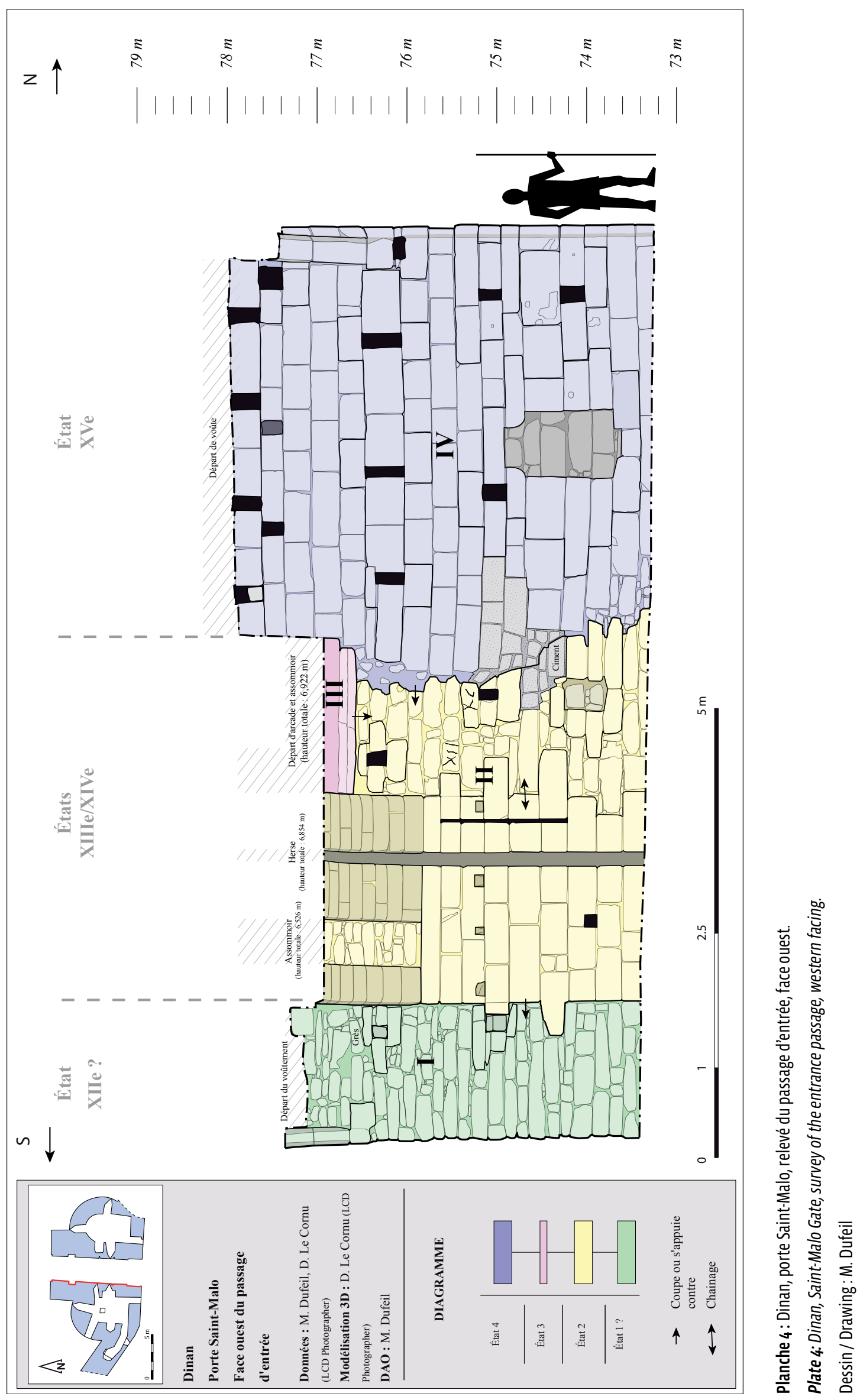


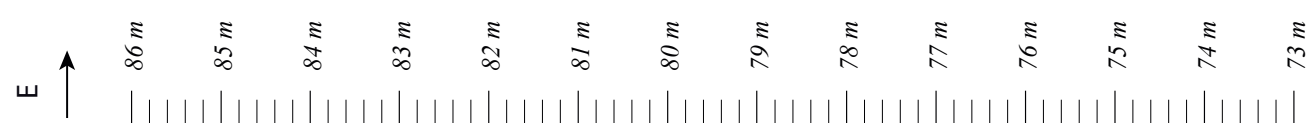

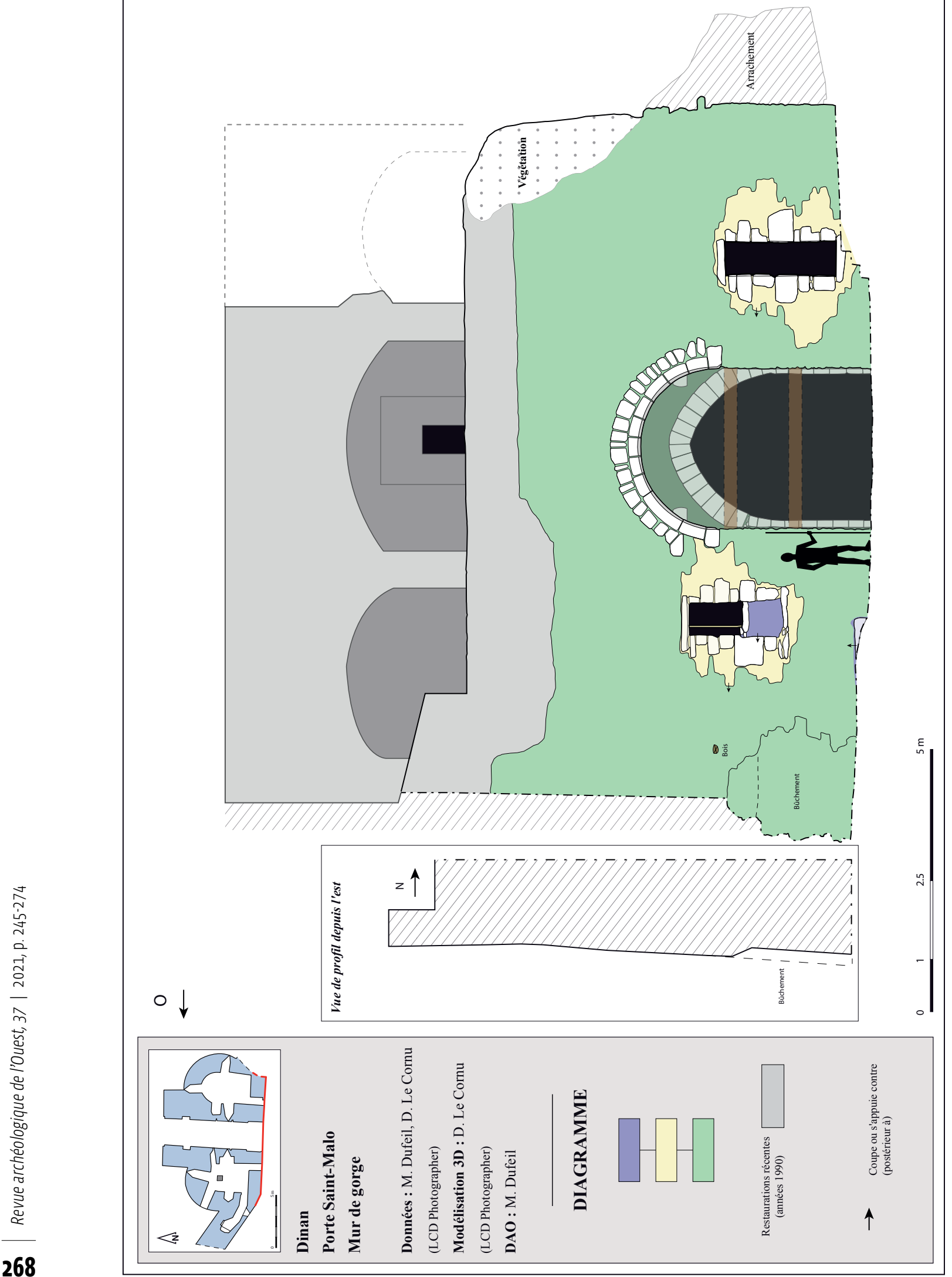

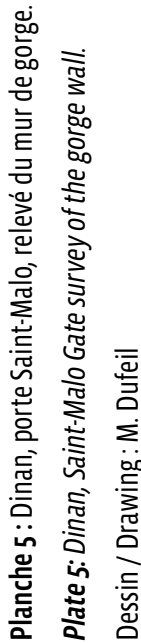




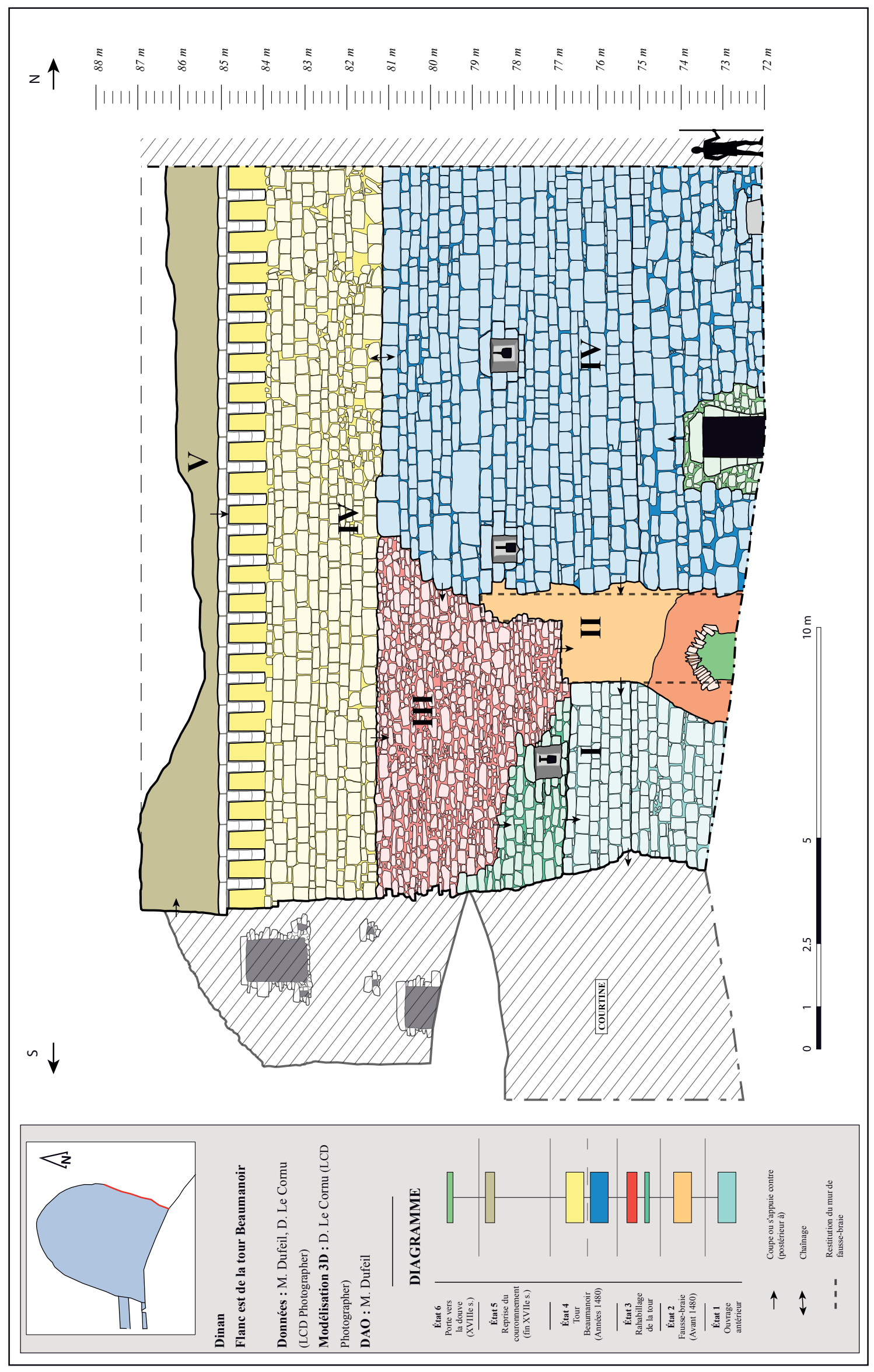

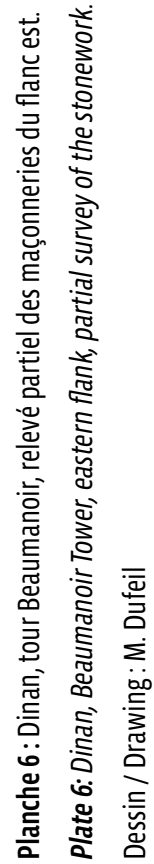


(fig. 15). Sans doute cette transformation intervient-elle tardivement, à un moment où l'usage de l'arc n'a plus cours, et où il est donc inutile de conserver les possibilités de tir offertes par les niches. C'est pourquoi il ne nous semble pas incohérent de dater cette reprise de la seconde moitié du $\mathrm{Xv}^{\mathrm{e}}$ s., en lien peut-être avec une diminution des fenêtres de tir par ajout d'un bahut d'allège, favorisant ici l'usage d'une arme épaulée. En parallèle, l'état des circulations est profondément remanié. Jusqu'ici dépendant du rez-de-chaussée, le cul-de-basse-fosse ménagé au bas de la tour ouest est dorénavant équipé d'une paire de portes, repercée au front et à la gorge de l'ouvrage. Cette évolution est sans doute consécutive à l'établissement d'un boulevard d'artillerie en avant de la porte. De façon assez fréquente en effet, une poterne de ce genre est prévue au bas des ouvrages d'entrée pour permettre, en cas d'invasion, le prompt retour des troupes affectées à la garde du boulevard (Faucherre, 2019, p. 119). Enfin, une dernière porte dérobée est aménagée sur le flanc de la tour ouest, à hauteur du N0. Succédant à une archère, cette poterne doit probablement mettre en communication l'intérieur de la porte Saint-Malo avec la fausse-braie établie à l'ouest.

\section{La modification des abords extérieurs dans la seconde moitié du $X V^{e} s$.}

Les abords de la porte Saint-Malo ont cela de remarquable qu'ils conservent une portion complète du système défensif mis en place dans la seconde moitié du $\mathrm{Xv}^{\mathrm{e}} \mathrm{s}$. (fig. 16). En avant de la place, le talus défensif subsiste sur environ $180 \mathrm{~m}$. Là, il domine sur plus de $4 \mathrm{~m}$ le niveau des douves remblayées et forme un premier cordon défensif, d'une épaisseur à peu près égale à $17 \mathrm{~m}$. Après quoi, un fossé d'environ $25 \mathrm{~m}$ sépare la contrescarpe du mur de fausse-braie, préservé ici sur plus de $40 \mathrm{~m}$ de long. Bâtie en avant du mur d'enceinte, la fausse-braie forme

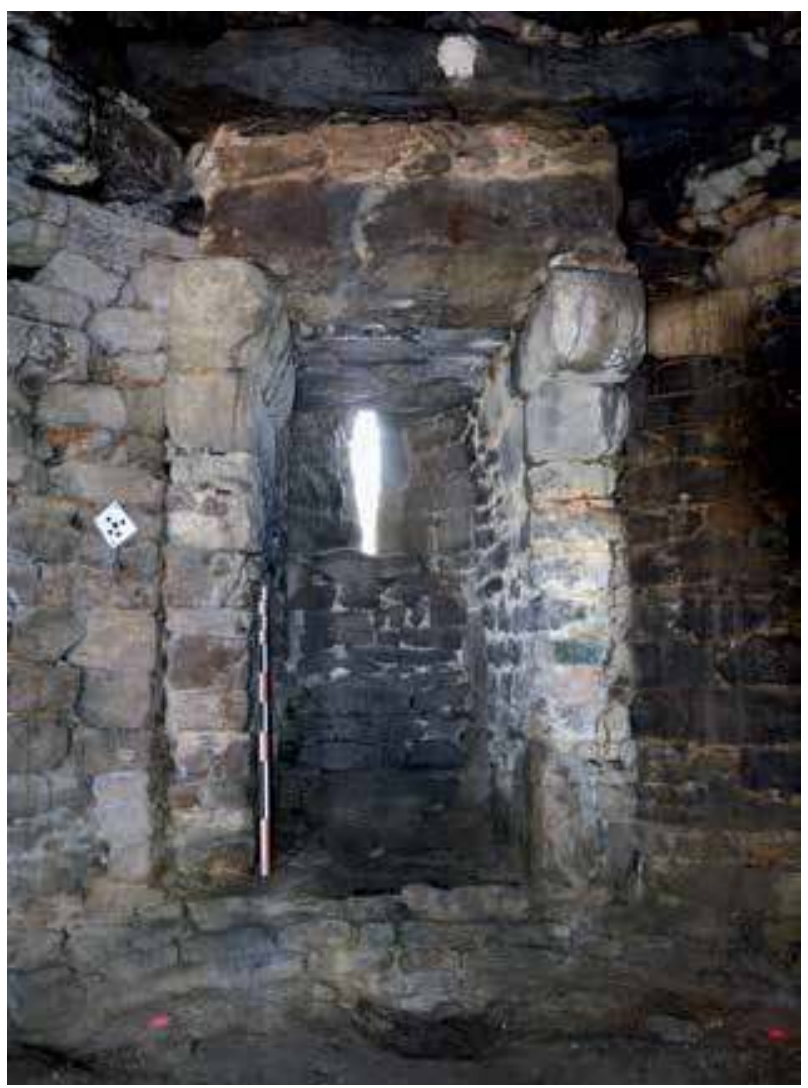

Figure 15: Dinan, porte Saint-Malo, premier niveau de la tour est. Figure 15: Dinan, Saint-Malo Gate, first level of the East tower. Cliché / Picture : M. Dufeil

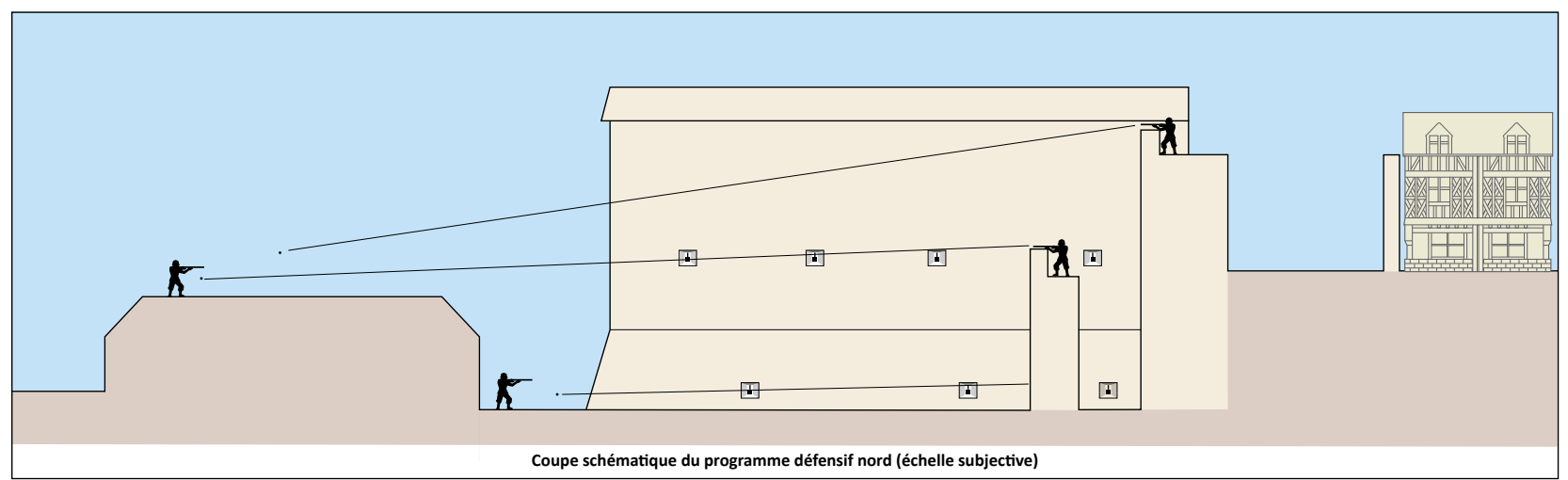

Figure 16 : Schéma restituant l'intégralité du système défensif présent sur le front nord de l'enceinte de Dinan, depuis le talus de contrescarpe (à gauche) jusqu'à la lice disposée au revers du mur d'enceinte (à droite).

Figure 16: Drawing showing the defensive system present on the northern of the wall of Dinan, from the counterscarp (on the left) to the service path placed on the back of the wall (on the right). 
une seconde ligne de défense sur deux niveaux : l'un pour battre le fond du fossé de front, l'autre pour défendre le sommet de la contrescarpe. À près de $3 \mathrm{~m}$ en retrait, une courtine haute de $12 \mathrm{~m}$ et épaisse de 3,70 m commande le mur de fausse-braie, qui lui-même préserve le pied de la muraille de toute entreprise de sape. En tête de courtine, quelques ouvertures de tir partiellement conservées témoignent de l'existence de défenses sommitales. La muraille constitue donc un troisième cordon défensif, prolongé en avant par la tour d'artillerie Beaumanoir. Enfin, côté ville, un second mur est élevé en parallèle à la courtine et à environ $7 \mathrm{~m}$ en retrait. Conservée sur près de $70 \mathrm{~m}$ de long, cette maçonnerie épaisse de $0,70 \mathrm{~m}$ paraît définir un espace de circulation au revers du mur d'enceinte.

D'après nos observations, le flanc est de la tour Beaumanoir conserve les restes d'un ouvrage antérieur, enchappé dans la construction actuelle (pl. 6). À première vue, les parements montés d'un côté et de l'autre $\mathrm{du}$ mur de fausse-braie entretiennent une relation distincte avec celui-ci, et une différence dans le rythme des assises montre qu'ils ont été élevés séparément. En outre, depuis l'intérieur de la tour, on constate que le rocher naturel qui affleure dans la partie postérieure de l'ouvrage décrit une courbe pouvant témoigner de l'existence d'un ouvrage circulaire de plus petite dimension, pour lequel on aura nivelé une fraction du socle rocheux. Selon toute vraisemblance, la tour Beaumanoir prend donc appui sur une tour antérieure, renforçant ainsi l'idée d'une construction hâtive. Certains indices tendent par ailleurs à confirmer que le mur de fausse-braie, postérieur à cette première tour de flanquement, serait à l'inverse antérieur à la tour Beaumanoir. Ainsi, on note que la destruction de la fausse-braie a entraîné, côté douve, l'arrachement des contours du parement de la tour, ce qui prouve que celuici était initialement appuyé contre le mur de fausse-braie. Selon toute vraisemblance, la fausse-braie pourrait bien être antérieure aux travaux des années 1480 .

\section{CONCLUSION}

Cet état des connaissances historique et archéologique permet de faire le point sur l'évolution chronologique et typologique des fortifications dinannaises. La plupart des sources documentaires disponibles tendent à prouver le développement rapide de l'agglomération de Dinan. Plusieurs bourgs monastiques semblent graviter autour du castrum seigneurial et une première clôture défensive est vraisemblablement érigée autour de celui-ci dès la première moitié du XII ${ }^{\mathrm{e}} \mathrm{s}$. Mentionnée dans les textes et peut-être en partie conservée dans le parcellaire ancien, l'existence de cette enceinte primitive reste encore à prouver sur le plan archéologique. Au XIII ${ }^{\mathrm{e}}$ s., les cadres topographiques définis au préalable servent de base à une nouvelle enceinte, peut-être bâtie à l'initiative du pouvoir ducal. Il est peu probable néanmoins que l'intégralité du périmètre fortifié ait été construite en dur dès cette époque. Sans doute a-t-on commencé par ériger certains des ouvrages les plus essentiels, à l'image des portes de ville. Plus tard, les épisodes guerriers des années 13421344 semblent avoir motivé la réalisation d'importants travaux de renforcement. En 1364, tout laisse à penser que la ville est entièrement bardée de murailles et prête à soutenir un long siège. $\mathrm{Au} \mathrm{Xv}^{\mathrm{e}}$ s., Dinan est une ville prospère qui se développe confortablement à l'intérieur de ses fortifications. À partir des années 1450 néanmoins, l'essor technique de l'artillerie et la montée grandissante des périls guerriers requièrent la réalisation de travaux de renforcement. L'attention se concentre en premier lieu sur le quart nord-ouest, où l'on édifie toute une série de tours d'artillerie. Après quoi, les efforts sont en partie redirigés vers le quart sud-ouest : à partir de la fin des années 1470 , le capitaine Jean II de Coëtquen supervise la construction des tours Penthièvre, de Coëtquen et du Connétable; puis, le front nord est à nouveau renforcé par les tours du Gouverneur et Beaumanoir. En parallèle, l'enceinte est protégée par une somme d'ouvrages avancés - boulevards d'artillerie, fausse-braie, levée de contrescarpe - et une desserte périphérique est peut-être installée au revers des courtines. Bénéficiant de la meilleure des protections, celle du relief, la moitié est de l'enceinte ne semble pas avoir été renforcée à cette occasion. Un siècle plus tard, dans le cadre des guerres de Religion, les défenses font l'objet de nouveaux travaux, menés dans l'urgence. La tour-résidence, autrefois bâtie sur commande du duc Jean IV, devient le cœur d'un réduit défensif, tourné tant vers l'extérieur que vers l'intérieur de la ville. Enfin, après quelques travaux de rénovation effectués sur ordre du roi à la fin du XVII ${ }^{e}$ s., les fortifications de Dinan tombent définitivement en désuétude. Cédées, afféagées puis peu à peu démolies au XVIII ${ }^{\mathrm{e}}$ s., elles serviront également de prison, avant d'être finalement classées au titre des Monuments historiques à la fin du xix ${ }^{e} s$.

L'étude archéologique réalisée aux abords de la porte Saint-Malo introduit quant à elle de nouvelles données. $\mathrm{Si}$, sur le plan architectural, l'ouvrage passe volontiers pour une production caractéristique de la fortification capétienne du XIII ${ }^{e}$ s., l'analyse archéologique suggère au contraire la subsistance d'un état plus ancien. De la même façon, l'observation des parements paraît révéler l'existence d'un ouvrage antérieur à la tour Beaumanoir, probablement inclus dans la construction actuelle, et resitue entre les deux la construction du mur de fausse-braie. In fine, l'analyse archéologique réalisée sur cette portion d'enceinte permet de mieux cerner l'évolution du front 
nord dans la seconde moitié du $\mathrm{Xv}^{\mathrm{e}}$ s. Plusieurs questions restent néanmoins en suspens quant à l'origine et à l'évolution des fortifications dinannaises, tandis qu'un certain nombre de sources restent peu ou pas exploitées ${ }^{23}$. Aussi, nous espérons que ce bilan des connaissances puisse servir les recherches à venir, qui viendront compléter, nuancer, voire corriger le propos développé dans ces pages.

\section{Remerciements}

Cet article, ainsi que le travail de recherche dont il est tiré, n'aurait pu voir le jour sans les avis, conseils et relectures de Pierre-Yves Laffont (professeur d'histoire et d'archéologie médiévale, université Rennes 2), Elen Esnault (archéologue du bâti, Inrap), Jean Mesqui (historien de l'architecture/castellologue, docteur ès-Lettres), Jocelyn Martineau (castellologue, SRA Pays de la Loire) et Emmanuel Litoux (archéologue du bâti, conservation départementale du patrimoine de Maine-et-Loire). Qu'ils en soient tous remerciés.

\section{Bibliographie}

Аміот C., 1999, Lignages et châteaux en Bretagne avant 1350, thèse de doctorat, université Rennes 2.

Aubry P., 1897, "Journal d'un bourgeois de Dinan ", Bulletins et Mémoires de la Société d'Émulation des Côtes-du-Nord, t. XXXV, p. 1-32.

Bachelier J., 2014, "Naissance et développement économique d'une ville castrale. Dinan aux $\mathrm{XI}^{\mathrm{e}}-\mathrm{XIII}^{\mathrm{e}}$ s. ", dans LAFFOnt P. -Y. (dir.), Les élites et leurs résidences en Bretagne au Moyen Âge, Rennes, Presses universitaires de Rennes, p. 209-223.

Barral i Altet X., 1986, "L'enceinte urbaine de Dinan ", dans Vilbert L.-R. (dir.), Dinan au Moyen Âge, éd. Le Pays de Dinan, p. 73-100.

Barral i Altet X., 1988, "Les archéologues du Xixe s. explorent Dinan : Prosper Mérimée, Arcisse de Caumont et Alfred Ramé ", Le Pays de Dinan, t. VIII, p. 63-80.

Barre du Nanteuil (De la) A., 1910, "Château de Tonquédec. Notice archéologique".

Barthélémy (DE) A. et Geslin de Bourgogne J., 1855-1879, Anciens évêchés de Bretagne, histoire et monuments, SaintBrieuc/Paris, $6 \mathrm{t}$.

Blanchard R., 1889-1895, Lettres et mandements de Jean V, duc de Bretagne de 1402 à 1442, Nantes, Société des Bibliophiles bretons, $5 \mathrm{t}$.

Beuchet L., 2014, " De la motte du comte à la forteresse ducale : le château de Guingamp (Côtes-d'Armor) ", Archéo-

23. La bibliothèque municipale de Dinan conserve un obituaire du XvI ${ }^{\mathrm{e}}$ S. relatif à la paroisse Saint-Sauveur. Deux documents rentiers du XVI ${ }^{\mathrm{e}}$. sont également conservés à Dinan et aux archives départementales de Loire-Atlantique. logie médiévale, t. 44, p. 71-123.

Beugnot Comte, 1839, Les olim ou registres des arrêts rendus par la cour du roi sous les règnes de Saint-Louis, Philippe le Hardi, Philippe Le Bel, Louis Le Hutin et Philippe Le Long, t. 1, 1254-1273, Paris, Imprimerie royale, 1149 p.

Bouchart A., 1886, Les grandes croniques de Bretaigne, Nantes, Société des Bibliophiles bretons, IV ${ }^{\mathrm{e}}$ fascicule.

Cornon R., 1950, "Dinan, architecture militaire et civile ", Congrès archéologique de France, p. 172-189.

Corvisier C., 1999, "Les ouvrages de la première époque ducale et les renforcements du $\mathrm{Xv}^{\mathrm{e}}$ s. à l'enceinte de Dinan en Bretagne ", dans Blieck G., Contamine P., Faucherre N. et Mesqui J. (dir.), Les enceintes urbaines (XIII -XVI s.), Paris, CTHS, p. 33-51.

Crouy-Chanel E. de, 2007, " La genèse du système bastionné ", dans Warmoes I. et SANger V. (dir.), Vauban, bâtisseur du Roi-Soleil, Cité de l'architecture et du patrimoine, p. 18-25.

Crouy-Chanel E. DE, 2020, Le canon (Moyen Âge-Renaissance), Tours, Presses universitaires François-Rabelais, coll. «Renaissance », 491 p.

Dom Morice P.-H., 1742-1746, Mémoires pour servir de preuves à l'histoire ecclésiastique et civile de la Bretagne, Paris, $3 \mathrm{t}$.

Dubuisson-Aubenay N., 1636, [rééd. 2000], Itinéraire de Bretagne en 1636, t. 1, Paris, éd. du Layeur, 352 p.

Dreillard C., 2017, "Les fortifications médiévales et modernes de la ville de Nantes : un état des connaissances historiques, archéologiques et topographiques ", Revue archéologique de l'Ouest, 34, p. 323-352.

Dufeil M., 2020a, La porte Saint-Malo de Dinan (Côtes-d'Armor), rapport de prospection thématique, SRA Bretagne, $198 \mathrm{p}$.

DufeIl M., 2020b, L'enceinte urbaine de Dinan (XIII -XVII s.), mémoire de master 2, université Rennes 2, 3 vol.

Esnault E., 2014, Les portes Mordelaises, rapport intermédiaire de fouille programmée, SRA Bretagne, $127 \mathrm{p}$.

Faucherre N., 2007, "Concarneau, la ville close. Une enceinte ducale de la seconde moitié du Xv ${ }^{\mathrm{e}}$ s. ", Monuments $d u$ Finistère, Congrès archéologique de France, $165^{\mathrm{e}}$ session, p. 65-83.

Faucherre N., 2016, "La tour du Fer à Cheval. Chant du cygne de la tour d'artillerie bretonne ", dans Guillet B. et Armide A. (dir.), Le château des ducs de Bretagne. Entre grandeur et renouveau. Huit siècles d'histoires, Rennes, Éditions du château des ducs de Bretagne/Presses universitaires de Rennes, p. 282-299.

Faucherre N., 2019, Les citadelles du roi de France sous Charles VII et Louis XI, Chagny, éd. du centre de castellologie de Bourgogne, $450 \mathrm{p}$.

Froissart J., 1991-1992, Chroniques, Livre I, le manuscrit d'Amiens, 3 t., éd. George T. Diller.

Geslin de Bourgogne J., 1870, «Dinan, notes archéologiques et historiques ", Bulletins et Mémoires de la Société 
d'émulation des Côtes du Nord, t. VIII, p. 19-34.

Gesret S., 1990, Les portes de Dinan, mémoire de maîtrise, université Rennes 2, 2 vol.

Gesret S., 1993, Les tours de Dinan, mémoire de DEA, université Rennes 2, 2 vol.

Gesret S., 1998, Les remparts de Dinan, Guingamp, éd. de la Plomée, 386 p.

Guigon P., 1990, "Le sarcophage du prieuré Saint-Malo », Le Pays de Dinan, t. X, p. 209-214.

Guinebaud S., 2011, "Dinan : place forte de la Ligue (15851598) ", Le Pays de Dinan, t. XXXI, p. 93-111.

Guitton L., 2007, «Un vicomte dans la cité : Jean II de Rohan et Dinan (1488-1516) ", Annales de Bretagne et des Pays de l'Ouest, t. 114-2, p. 7-37.

Hamon F., 1976, Les fortifications dinannaises au XVIIT s., mémoire de maîtrise, université de Haute-Bretagne, Institut armoricain de recherches historiques, 119 p.

Науот D., 2015, L'architecture fortifiée capétienne au XIIt s. (1180-1270), thèse de doctorat, université Paris IV.

Науот D., 2017, "Le château de Léhon ", Monuments des Côtes-d'Armor, Le "Beau Moyen Âge ", Congrès archéologique de France, $173^{\mathrm{e}}$ session, p. 85-95.

Hunot J.-Y., 2015, « Angers (Maine-et-Loire). Place MichelDebré ", Archéologie médiévale, t. 45 [notice archéologique consultée en ligne].

IDRĪsī, 1999 (réed.), La première géographie de l'Occident, Paris, Flammarion, $516 \mathrm{p}$.

Jones, 1996, Recueil des actes de Charles de Blois et de Jeanne de Penthièvre, Rennes, Presses universitaires de Rennes, coll. "Histoire », 300 p.

La Borderie A. DE, 1890, "Documents inédits sur l'histoire de la ville de Dinan ", Revue de Bretagne, de Vendée et d'Anjou, t. IV, p. 139-143.

La Borderie A. DE, 1891, Miracles de S. Magloire et fondation du monastère de Léhon, Rennes, 139 p.

Le Giemble abbé, non daté ( $\mathrm{xIx}^{\mathrm{e}} \mathrm{s}$.), Les sires de Dinan. Chronique de Dinan sous ses seigneurs particuliers (1040-1341), (photocopie de manuscrit conservée à la BMD, 39.570).

LeguaY J.-P., 1981, Un réseau urbain au Moyen Âge: les villes du duché de Bretagne aux XIV et XV s., Paris, éd. Maloine, $406 \mathrm{p}$.

Leguay J.-P., 1986, "Dinan au temps des ducs, de 1283 à 1532 ", dans Vilbert L.-R. (dir.), Dinan au Moyen Âge, éd. Le Pays de Dinan, p. 31-62.

Leguay J.-P. et Martin H., 1982, Fastes et malheurs de la Bretagne ducale 1213-1532, Rennes, éd. Ouest-France, 435 p.

LÉmeillat M., 2014, Actes de Jean I ${ }^{e r}$, Presses universitaires de Rennes, coll. «Sources médiévales de l'histoire de Bretagne », Société d'histoire et d'archéologie de Bretagne, 390 p.
Limon J. M. P. A., 1852, Usages et règlements locaux en vigueur dans le département du Finistère, Quimper, imprimerie de Lion, 493 p.

Maheo M., 1852, Notice historique sur le château de Dinan, Société archéologique et historique des Côtes du Nord, 36 p.

Martineau J., 2011, "Les tours à canon du duché de Bretagne au Xve s. ", dans Prouteau N., De Crouy-Chanel E. et Faucherre N. (dir.), Artillerie et fortification 1200-1600, Rennes, Presses universitaires de Rennes, p. 157-163.

Martineau J., 2016a, "Fortifier le château des ducs de Bretagne au Xve s. ", dans Guillet B. et Armide A. (dir.), Le château des ducs de Bretagne. Entre grandeur et renouveau. Huit siècles d'histoires, Rennes, Éditions du château des ducs de Bretagne/Presses universitaires de Rennes, p. 245-282.

Martineau J., 2016b, "Quelles armes pour défendre quelle forteresse? ", dans Guillet B. et Armide A. (dir.), Le château des ducs de Bretagne. Entre grandeur et renouveau. Huit siècles d'histoires, Rennes, Éditions du château des ducs de Bretagne/Presses universitaires de Rennes, p. 300-314.

Martineau J. et Bellanger P., 2017, «Le château de la Groulais à Blain ", Bulletin de la Société archéologique et historique de Nantes et de Loire-Atlantique, Nantes, p. 95-128.

Ménez Y., 1991, Dinan, place Duclos, rapport de sondages archéologiques, SRA Bretagne, $9 \mathrm{p}$.

MÉnez Y., 1993, Dinan, place Duclos, rapport de sondages archéologiques, SRA Bretagne, $3 \mathrm{p}$.

Meazey P., 1997, Dinan au temps des seigneurs, Guingamp, éd. de la Plomée, 192 p.

Mesqui J., 1991, Châteaux et enceintes de la France médiévale: De la défense à la résidence, $\mathrm{t}$. I : "Les organes de la défense ", Paris, Picard, 375 p.

Mesqui J., 1993, Châteaux et enceintes de la France médiévale: De la défense à la résidence, $\mathrm{t}$. II : « La résidence et les éléments d'architecture ", Paris, Picard, 382 p.

Mesqui J., 1997, Châteaux forts et fortifications en France, Paris, Flammarion, $494 \mathrm{p}$.

Mesqui J., 2017, "Les châteaux et la ville forte de Dinan ", Monuments des Côtes-d'Armor, Le "Beau Moyen Âge ", Congrès archéologique de France, $173^{\mathrm{e}}$ session, p. 53-84.

Monier M.-E., 1977, Dinan mille ans d'histoire, Dinan, 1968, $2^{\mathrm{e}}$ éd., $582 \mathrm{p}$.

Morin S., 2010, Trégor, Goëlo, Penthièvre. Le pouvoir des Comtes de Bretagne du XI au XIII s., Presses universitaires de Rennes, Société d'émulation des Côtes-d'Armor, 293 p.

Ronsseray D., 1986, "Les remparts de Dinan ", Monuments historiques, $\mathrm{n}^{\circ} 146$, p. 97-112.

Stephant J., 1947, Dinan. Étude de géographie urbaine, mémoire de DES, université de Haute-Bretagne, 189 p. 
MICKAËL DUFEIL

Die mittelalterlichen und neuzeitlichen Befestigungsanlagen von Dinan (Côtes-d'Armor): eine Übersicht zum historischen und archäologischen Forschungsstand

Diese Untersuchung, die sich auf die schriftlichen Primärquellen, auf ikonographische Darstellungen, alte Pläne sowie auf die wichtigsten architektonischen Elemente und Charakteristika der erhaltenen Befestigungsanlagen stützt, hat zum Ziel, den aktuellen Forschungsstand historischer und archäologischer Erkenntnisse zu den mittelalterlichen, frühneuzeitlichen und modernen Stadtbefestigungen von Dinan darzustellen. Die großen Etappen der Entwicklung der Befestigungsanlagen sowie die morphologische Entwicklung des Stadtgrundrisses werden diskutiert, beispielsweise die erste Wallanlage, die vermutlich während des 12. Jh. angelegt wurde, die Errichtung einer großen Stadtmauer im 13.-14. Jh., die Verstärkung und Anpassung der Befestigungsanlagen an die neu aufkommende Artillerie in der zweiten Hälfte des 15. Jahrhunderts, die Anlage einer städtischen Zitadelle am Ende des 16. Jh. sowie eine Wiederaufnahme der Befestigungsarbeiten am Ende des 17. Jh. Schließlich präsentiert der vorliegende Beitrag die Ergebnisse einer ersten bauarchäologischen Untersuchung eines Teils der nördlichen Stadtbefestigung, im Bereich des Stadttores von SaintMalo und in seinem Umfeld. Diese Untersuchung, die im Rahmen einer Forschungsgrabung durchgeführt wurde, stellt einige bisher unpublizierte Hypothesen zur Herkunft und zur Entwicklung dieses Teils der Stadtbefestigung vor, die wiederum neue Fragestellungen eröffnen.

Schlagwortindex: Dinan, Verteidigungswälle, Stadtbefestigung, Burganlage, Befestigungsarbeiten, Artillerie, Bretagne, Mittelalter, Bauarchäologie. 